\title{
Towards Designing Anisotropy for Ductility Enhancement: A Theory-Driven Investigation in Mg-alloys
}

\author{
Shamik Basu ${ }^{\mathrm{a}}$, E. Dogan ${ }^{\mathrm{b}}$, B. Kondori ${ }^{\mathrm{a}}$, I. Karaman ${ }^{\mathrm{a}, \mathrm{b}}$, A. A. Benzerga ${ }^{\mathrm{a}, \mathrm{c}, *}$ \\ ${ }^{a}$ Department of Materials Science and Engineering, Texas A\&M University, College Station, TX \\ 77843-3003, United States \\ ${ }^{b}$ Department of Mechanical Engineering, Texas A\&M University, College Station, TX 77843-3123, United \\ States \\ ${ }^{c}$ Department of Aerospace Engineering, Texas A\&M University, College Station, TX 77843-3141, United \\ States
}

\begin{abstract}
Plastic anisotropy is often invoked to rationalize low formability in strongly anisotropic materials. Analysis based on homogenization theory suggests, however, that certain forms of plastic anisotropy may hinder ductile damage under any triaxial stress state or loading orientation. Here, a proof-of-concept is demonstrated in the case of Mg alloys. Two textures produced by severe plastic deformation of Mg-3Al-1Zn alloy, while keeping the grain sizes nearly the same, are compared with the well-known rolling texture in terms of their anisotropy-ductility correlations at room temperature. For each material, the 3D plastic anisotropy is characterized using tensile and compression specimens whereas the ductility is determined using smooth and round notched tensile bars. A simple micromechanical model is proposed to rationalize the trends. The main finding suggests that plastic anisotropy can be altered to aid ductility. Perspectives for how to harness anisotropy in material design are presented.
\end{abstract}

${ }^{*}$ Corresponding author, Phone: 979-845-1602 ; Fax: 979-845-6051

Email address: benzerga@tamu.edu (A. A. Benzerga)

(C) 2017. This manuscript version is made available under the Elsevier user license http://www.elsevier.com/open-access/userlicense/1.0/ 


\section{Introduction}

Plastic anisotropy is often invoked to rationalize the low formability/ductility of magnesium alloys at low homologous temperatures $[1,2]$. Mg alloys are inherently anisotropic as a result of their hexagonal-close-packed crystalline structure. Conventional thermomechanical processing, such as rolling, leads to sharp crystallographic textures and associated anisotropy at the polycrystalline level [3,4]. This anisotropy is due to large differences in critical resolved shear stresses (CRSS) of basal and non-basal slip systems with the non-basal slip activated only at elevated temperatures [5]. The activated systems are often too few to satisfy the basic strain compatibility criteria [6]. Thus, the anisotropy-induced incompatibility in plastic deformation is believed to trigger stress concentrations, hence failures [7]. Twinning is an additional mode of deformation that helps satisfy the Taylor criterion $[8,9]$. However, twinning is a polar mechanism that can only accommodate deformation under specific loading conditions. In addition, the twinned volume undergoes sudden reorientation and this may lead to strain localization, hence failure $[10,11]$.

In the last two decades, much effort has been dedicated to alleviating the negative effects of anisotropy on the plastic flow behavior of Mg alloys. Research has focused on revealing the complex deformation mechanisms as a function of chemistry and texture $[3,7,12-16]$. As a result, two major approaches have emerged which aim at suppressing or reducing the anisotropy via structural manipulations. The first consists of micro-alloying so as to narrow down the wide gap among the CRSS values of the various deformation systems, for example through the type, shape and habit planes of precipitates [2, 17-19]. For instance, alloying by rare-earth elements has been shown to generate weak textures, as opposed to rare-earth free $\mathrm{Mg}$ alloys [2, 19]. In turn, improvement in strength was achieved without compromising uniaxial ductility [20-22]. In addition, RE based alloys such as WE43 (Mg4Y-3RE) are plastically quasi-isotropic with no noteworthy tension-compression asymmetry $[23,24]$. What is less emphasized in the literature, however, is that the removal of plastic flow anisotropy in RE alloys is not accompanied by an enhancement in formability 
or ductility, which makes the connection between strong anisotropy and poor ductility questionable. In fact, Kondori and Benzerga [25] have recently shown that the notch ductility of WE43 is much reduced compared with that of rare-earth free AZ31 Mg alloy. It appears, therefore, that mere texture weakening -thanks to microalloying and precipitation- may not be the engineering solution of choice to enhance the ductility of Mg alloys.

Another approach to mitigating plastic anisotropy has consisted of thermo-mechanical processes, such as equal-channel angular extrusion (ECAE), a method of severe plastic deformation [26, 27]. Mukai et al. [28] showed that ECAE followed by annealing at $300^{\circ} \mathrm{C}$ improved the ductility of initially textured AZ31 alloy along the extrusion direction by more than twofold. They attributed the improvement in ductility to a presumably random texture, induced by the specifically chosen ECAE route $\left(4 \mathrm{~B}_{\mathrm{c}}\right)$ and post-ECAE annealing. Agnew et al. [29] repeated the same experiments and confirmed the ductility enhancement along the extrusion direction. However, these authors performed, in addition, uniaxial tests along various principal and off-axes directions. The data in [29] showed clear evidence of directionality in plastic flow, consistent with a distinct texture, albeit different from the starting rolling (basal) texture. The data in [29] also revealed that while the ductility was lower in one particular orientation, all other orientations were either comparable or better than the as-received alloy. Agnew et al. concluded that ECAE produces stronger texture than some of the conventional processing methods. However, they did not provide a rationale for the increase in ductility observed in most directions when compared to as-rolled AZ31. More recent work along these lines has confirmed the mechanical anisotropy associated with ECAE-processed materials [16, 30], showed the effect of grain-size reduction on prismatic slip [31], and the reduction in tension-compression asymmetry [32].

The above two findings, namely (i) the lack of success in improving room temperature ductility by weakening / randomizing the texture through microalloying and precipitation; and (ii) the (unexplained) increase in ductility concurrent with strong anisotropy, indicate that anisotropy-ductility relationships are more complex than previously believed. The early findings in [28] and [29] showed promise but clearly have not been capitalized upon. The 
aim of this work is therefore, to develop a mechanistic framework within which contradicting effects of plastic anisotropy on ductility can be rationalized, irrespective of the inherent directionality in properties. The basis of this rationale is as follows. Contingent upon the activation of ductile failure by void growth to coalescence [33], a mean-field analysis based on homogenization theory suggests that certain forms of plastic anisotropy may hinder void growth under any triaxial stress state or loading orientation [34]. For relatively simple forms of anisotropy that ignore tension-compression asymmetry altogether, the resistance to void growth depends to first order upon a scalar invariant of the anisotropy tensor [34]. This scalar is here referred to as the Anisotropy Effect on Ductility (AED) index, which will be defined in detail in the following section. The fundamental hypothesis of this work is that this AED index can be tuned through processing to enhance ductility at comparable strength levels.

To test the hypothesis, three materials with potentially different degrees of plastic anisotropy were used. The first is as-received hot-rolled AZ31 Mg alloy. The other two were processed using ECAE, which has proven effective in altering textures in addition to the usual grain refinement $[11,29]$. To isolate the effect of texture, all processed materials were heat treated to restore the hardening capacity and grow the grain size back to the regime of the as-rolled material. Plastic flow anisotropy was characterized in full 3D, both in compression and tension. The AED index was thus calculated for each material/texture. Next, the ductility of each material was characterized using (i) uniaxial tension specimens cut along various directions; and (ii) round notched bars cut along the extrusion direction. The first set of data enables probing directionality of ductility whereas the second set allows one to explore the effect of triaxiality on ductility as in [35]. Finally, correlations between two measures of fracture strain and the AED index were sought and rationalized on the basis of the micromechanistic model. 


\section{Theory}

The hypothesis underlying this work is that the plastic anisotropy of $\mathrm{Mg}$ alloys can be modified to deliver materials with enhanced ductility at comparable strength. The basis for this is the theory of void growth in anisotropic materials, as articulated in [34, 36] and further developed in [37-40]. Consider for simplicity a Hill-type material with no tension/compression asymmetry. The yield condition reads:

$$
\sigma_{\text {eq }}^{2} \equiv \frac{3}{2} \mathbf{s}: \text { h }: \mathbf{s}=\bar{\sigma}^{2}
$$

where $\sigma_{\text {eq }}$ is the Hill equivalent stress, $\mathbf{s}$ is the stress deviator, h is the fourth order anisotropy tensor, and $\bar{\sigma}$ is the flow stress in an arbitrarily chosen reference direction. In axes pointing onto the principal directions of orthotropy, the above equation can be expanded into the following explicit form:

$$
\sigma_{\text {eq }}^{2}=\frac{3}{2}\left(h_{1} s_{11}^{2}+h_{2} s_{22}^{2}+h_{3} s_{33}^{2}+2 h_{4} s_{23}^{2}+2 h_{5} s_{31}^{2}+2 h_{6} s_{12}^{2}\right)=\bar{\sigma}^{2}
$$

where the anisotropy coefficients $h_{i}$ are related to those used by Hill [41]; see [34] and [42] for further details.

The micromechanics of void growth in anisotropic materials of the type shown in equation (2) is captured in the following equation [34, 43]:

$$
\frac{\dot{f}}{\dot{\epsilon}_{\mathrm{eq}} f} \approx \frac{3}{h} \sinh \left(\frac{3}{h} T\right)
$$

where $f$ is the void volume fraction, $\dot{\epsilon}_{\text {eq }}$ is the effective plastic strain rate, $T$ is the stress triaxiality ratio, and $h$ is a scalar invariant of tensor $\mathrm{h}$ used in equation (1). In terms of the $h_{i}$ coefficients entering the yield condition (2), this scalar invariant is given by

$$
h=2\left[\frac{2}{5} \frac{h_{1}+h_{2}+h_{3}}{h_{1} h_{2}+h_{2} h_{3}+h_{3} h_{1}}+\frac{1}{5}\left(\frac{1}{h_{4}}+\frac{1}{h_{5}}+\frac{1}{h_{6}}\right)\right]^{\frac{1}{2}}
$$

Equation (3) shows that the rate of growth of porosity, $\dot{f}$, in a plastically deforming material 
is dependent on the 'degree of anisotropy' of the material, as lumped in the $h$ factor. This factor is a potent one since it appears inside the exponential term. Thus, small changes in $h$ could lead to large variations in void growth rate. Examination of equation (4) reveals that $h=2$ for an isotropic von Mises material (since all $h_{i}$ 's are then equal to 1 ). According to this theory, values of $h$ greater than 2 would decrease the porosity growth rate, on average, while values less than 2 would lead to an increase in porosity growth rate. This would hold for any triaxiality $T$ and most, if not all loading directions. Hence, the $h$ factor may be used as an index for the anisotropy effect on ductility. In what follows, we shall refer to it as the AED index.

In practice the $h_{i}$ coefficients are determined either based on yield stresses or anisotropy strain ratios. The two methods deliver the same set of values insofar as Schmid's law holds. For example, Benzerga [42] developed the equations relating the $h_{i}$ coefficients to the strain ratios. These relations are recalled in Appendix A using notation from Section 3.3.2 below. The dual relations in terms of yield stresses may be found, for example, in [44].

A quadratic yield criterion such as (2) has obvious limitations when it comes to modeling the anisotropy in $\mathrm{Mg}$ alloys. It is assumed therefore that the AED index (or $h$ factor) is robust enough to be applied to more complex materials. Note that in some Mg alloys, the tension-compression asymmetry gradually decreases upon straining, although it is large initially. It is emphasized that the objective here is to estimate the AED index on the basis of the Hill anisotropy coefficients that provide the closest fit to experimental data, not advocate using a quadratic yield criterion to model the plasticity of Mg. Better constitutive models are now available, e.g., see [45-47] and references therein. However, for such constitutive models the relationships between model parameters and anisotropy strain ratios are not readily available in closed form. In addition, void growth equations are not currently available, and seem out of reach, for such advanced plasticity models. Hence, these models are not amenable to implementing a similar ductility-index based methodology. 


\section{Experimental Procedure}

\subsection{Materials}

The as-received material is a commercial AZ31B (H24 temper) $\mathrm{Mg}$ alloy with the nominal composition of $3.33 \mathrm{Al}, 0.88 \mathrm{Zn}, 0.21 \mathrm{Mn}$, balance $\mathrm{Mg}$ (all in \%wt) in the form of hot rolled $25.4 \mathrm{~mm}$-thick plate. The microstructure and two pole figures are shown in Fig. 1. The material has an average grain size of $20 \mu \mathrm{m}$ and a distinct basal texture. The principal directions of the plate are referred to as $\mathrm{R}, \mathrm{T}, \mathrm{N}$ for rolling, transverse and normal directions, respectively (Fig. 2a). In order to produce materials having the same average grain size but different texture-induced plastic anisotropies, severe plastic deformation was used by means of equal-channel angular extrusion (ECAE). Two $25 \mathrm{~mm} \times 25 \mathrm{~mm} \times 150 \mathrm{~mm}$ billets were cut from the hot rolled plate and passed through a $90^{\circ}$ ECAE die with sharp corners (Fig. 2b). A backpressure of $20 \mathrm{MPa}$ and an extrusion rate of $4.57 \mathrm{~mm} / \mathrm{min}$ at $200^{\circ} \mathrm{C}$ were used to process the material without causing surface cracks. Two routes were used with multiple (four) passes to obtain different textures. In route A, the billet orientation is not changed between two successive passes, while for route $\mathrm{C}$ the billet is rotated by $180^{\circ}$ about the extrusion axis after each pass [27]. The resulting materials, which are known to have different textures [16] are referred to as $4 \mathrm{~A}$ and $4 \mathrm{C}$, respectively. For the ECAE processed materials, the principal directions are denoted E, F and L for the extrusion, flow and longitudinal directions, respectively (Fig. 2b).

The materials obtained after ECAE have small grain sizes on the order of 1 to 4 micron [16]. In order to compare the processed materials with the as-received one, the processed billets were heat treated for 24 hours at $350^{\circ} \mathrm{C}$ so as to grow the grain size back to its initial value in the as-received plate. With this procedure, the grain size is nominally controlled and the only independent variable is the texture, hence the degree of plastic anisotropy. A line intercept method was used to determine the average grain size. X-ray diffraction (XRD) was used at time intervals of 0,2,10 and 24 hours during annealing to monitor any possible changes in the processing induced texture for each route. This was accomplished 
by using small coupons of 4A and 4C material taken from the billet's mid-section in a Bruker-AXS D8 X-ray diffractometer with $\mathrm{Cu} \mathrm{K} \alpha$ radiation using a $5^{\circ}$ step size and up to $85^{\circ}$ sample tilt.

\subsection{Microstructure characterization}

Optical microscopy was used to characterize the initial and processed microstructures. Metallographic sections from different planes were prepared by cutting samples using a diamond saw, ground with $\mathrm{SiC}$ paper and fine polished using $1 \mu \mathrm{m}$ diamond solution and $0.3 \mu \mathrm{m}$ colloidal silica suspensions. Water was used during grinding only. The solutions used for fine polishing were alchohol based; this includes the diamond solution and the lubricant. Ethanol was used for rinsing and acetone as ultrasonic cleanser. For etching, acetic picral solution ( $4.2 \mathrm{~g}$ picric acid, $10 \mathrm{ml}$ acetic acid, $70 \mathrm{ml}$ ethanol and $10 \mathrm{ml}$ water) was used for time periods up to $5 \mathrm{~s}$. The materials that were processed without annealing had a quicker response to the etching process due to the higher stored energy from processing.

\subsection{Mechanical Tests}

\subsubsection{Uniaxial Tests}

From each billet, round compression and flat tension dog-bone specimens were cut out along the three principal directions $\mathrm{E}, \mathrm{F}$ and $\mathrm{L}$ in addition to three off-axes directions, at $45^{\circ}$ from a principal direction in a principal plane. Each off-axis direction is referred to using the two letters defining the principal plane. For example, EF is the direction at $45^{\circ}$ from $\mathrm{E}$ in the E-F plane. Cylindrical specimens are generally preferred in characterizing anisotropy [35]. However, due to the limited availability of material, flat specimens had to be used in tension. Two specimens were used per test condition. The geometry of the specimens used is shown in Figs. 3a-b. Since ECAE leads to undeformed ends in the billets,

these ends were truncated and all specimens were carved out of regions of (nominally) uniform deformation. The tensile bars of the as-received material were round as shown in Fig. 3c. 
All tests were performed at room temperature on a MTS servo-hydraulic frame at a nominal strain rate of $5 \times 10^{-4} \mathrm{~s}^{-1}$. The axial strain was measured in tension using a MTS axial extensometer. For compression a nickel based lubricant was used to prevent early barreling. All compression pins failed in shear and broke in two pieces. The fracture strain in compression was well estimated at the abrupt load drop. In tension, however, the strain to failure was also measured based on area reduction after fracture to account for (i) post-necking deformation; and (ii) the ovalization of cross-sections due to plastic anisotropy.

\subsubsection{Measurement of Anisotropy Ratios}

Given a loading orientation, say L, and a loading mode (tension or compression) define the true axial and transverse strains as follows:

$$
\varepsilon_{\mathrm{L}}=\ln \left(\frac{H}{H_{0}}\right) ; \quad \varepsilon_{\mathrm{X}}=\ln \left(\frac{\Phi_{\mathrm{X}}}{\Phi_{0}}\right)
$$

where $H$ and $H_{0}$ denote current and initial gage heights, respectively, $\mathrm{X}$ refers to a transverse direction (either $\mathrm{E}$ or $\mathrm{F}$ when loading along $\mathrm{L}$ ), and $\Phi_{\mathrm{X}}$ and $\Phi_{0}$ are the current and initial diameters, respectively. In pin compression, initially circular cross-sections become oval so that $\Phi_{\mathrm{X}}$ refers specifically to the "oval's diameter" along X. In flat tensile specimens, $\Phi_{\mathrm{X}}$ refers to either the width or thickness of the current cross-section.

With that as basis, the anisotropy strain ratio for loading along $\mathrm{L}$ is then defined as

$$
R^{\mathrm{L}}=\frac{\dot{\varepsilon}_{\mathrm{E}}}{\dot{\varepsilon}_{\mathrm{F}}} \approx \frac{\varepsilon_{\mathrm{E}}}{\varepsilon_{\mathrm{F}}}
$$

The other two strain ratios, $R^{\mathrm{E}}$ and $R^{\mathrm{F}}$, are defined following a cyclic permutation $(\mathrm{E}, \mathrm{F}, \mathrm{L})$ $[42,44]$. For off-axis loading, say along the EF direction, the anisotropy strain ratio is conveniently defined as:

$$
R^{\mathrm{EF}}=\frac{\varepsilon_{\mathrm{FE}}}{\varepsilon_{\mathrm{L}}}
$$

where the FE direction stands for the dual direction perpendicular to EF in the E-F plane. The other two off-axis strain ratios, $R^{\mathrm{FL}}$ and $R^{\mathrm{LE}}$, are defined in a similar way. These strain 
ratios are akin the so-called Lankford coefficients, albeit the definitions differ. They also generalize the notion of $r$-value used in sheet metal forming.

To enable the measurement of diameters $\Phi_{\mathrm{X}}$ entering the definition of transverse (or lateral) strains in equation (5) all compression tests were interrupted multiple times. Fewer interruptions were made in tension, typically two or less, including just before the macroscopic load drop. All dimensions were measured using a high-precision micrometer so that strains were measured with an accuracy of $0.1 \%$. Once the strain ratios were determined, the anisotropy coefficients $h_{i}$ were obtained using the equations of Appendix A, then used to determine the AED index $h$ of equation (4) rewritten in the billet axes as:

$$
h=2\left[\frac{2}{5} \frac{h_{\mathrm{E}}+h_{\mathrm{F}}+h_{\mathrm{L}}}{h_{\mathrm{E}} h_{\mathrm{F}}+h_{\mathrm{F}} h_{\mathrm{L}}+h_{\mathrm{L}} h_{\mathrm{E}}}+\frac{1}{5}\left(\frac{1}{h_{\mathrm{FL}}}+\frac{1}{h_{\mathrm{LE}}}+\frac{1}{h_{\mathrm{EF}}}\right)\right]^{\frac{1}{2}}
$$

As a measure of tensile ductility, the strain to failure $\varepsilon_{\mathrm{f}}$ is defined as the sum of the lateral logarithmic strains, for example for tension along $\mathrm{L}$ as follows:

$$
\varepsilon_{\mathrm{f}}^{\mathrm{L}}=\ln \left(\frac{\Phi_{\mathrm{E}}}{\Phi_{0}}\right)+\ln \left(\frac{\Phi_{\mathrm{F}}}{\Phi_{0}}\right)
$$

\subsubsection{Round Notched Bar Test}

Round cylinders were also cut using wire electro-discharge machining (EDM) along the extrusion direction. From these cylinders, axisymmetric notched bars were machined. Notched bars are usually employed in fracture studies [48, 49]. In strongly anisotropic materials such as $\mathrm{Mg}$, introduction of a notch plays a dual role since it also allows to investigate the effect of triaxial loading on the mechanical anisotropy. Since the stress state is triaxial inside the notch, there are two equal minor principal stresses $\sigma$ in addition to the major axial stess $\Sigma>\sigma$. A notch severity parameter, $\zeta$, is introduced as:

$$
\zeta=10 * \frac{R}{\Phi}
$$


with $R$ the notch radius and $\Phi$ the notch root diameter as shown in Fig. 3d. All specimens used here had $\zeta=10$.

Taking the notch height as a gauge length, a nominal strain rate of $3 \times 10^{-4} s^{-1}$ was imposed in all cases. In the notched bars, the use of an axial extensometer could lead to ambiguity in interpreting the results as plastic flow is generally confined to the notch. Instead, continuous measurement of diameter reduction was made using a custom made radial extensometer having knives mounted on a MTS clip-on gage, as described in [35, 50]. Since the studied material is anisotropic and only one such extensometer can be positioned at the notch root, each test was interrupted multiple times and measurements along the other principal direction were recorded. Definition $(5)_{2}$ is used for the lateral strains at the notch root. Crack initiation is detected by an abrupt change in the macroscopic slope in the load versus diameter reduction curve and defines the strain to failure; see e.g. [43] for a rationale and restrictions.

\subsection{Fractography}

All surfaces of fractured notched specimens were observed using the scanning electron microscope (SEM) FEI model Quanta 600. Since Mg alloys in general are notorious for quickly oxidizing in air the surfaces were observed shortly after each experiment. The surfaces were sprayed with silicone immediately after fracture and placed in desiccators under vacuum prior to observations. Yet, each sample could be observed only once even with care taken to prevent oxidation.

After the fracture surfaces were observed in SEM, one half of the specimen was sectioned longitudinally using EDM and metallographically prepared and observed under both OM and SEM in the E-F and E-L planes. The aim was to observe the extent of damage beneath fracture surfaces. Fine polishing was done as described above with particular care given so as not to smear out voids smaller than a few microns in size. When voids were found to initiate at second-phase particles, electron dispersion spectroscopy was used to characterize their composition. Similar techniques were used in $[35,51]$. 


\section{Results}

\subsection{Processed Textures and Microstructures}

The textures obtained by ECAE processing are compared in Fig. 4 with the as-rolled texture. That of material 4A has rotational symmetry about the flow direction. A single pass through route A leads to a rolling-like texture. Subsequent route-A passes strengthen this texture by reorientation to a very similar texture after each pass [52]. On the other hand, route $\mathrm{C}$ is a redundant strain path whereby the direction of simple shear is reversed after each pass. However, the second pass does not erase the texture developed in the first, demonstrating path dependence in deformation induced textures [52]. The pole split occurs after the first pass. Each pass after that strengthens one of the pole fiber directions. This is because, in this route, the shear plane remains the same, although the direction along which the grains shear reverses after each pass.

The outcome of the post-processing heat treatment is shown in Figure 5 for material 4A. The as-processed material exhibits a fine grain microstructure (Fig. 5a) with few large grains elongated along the extrusion direction, as often reported for this particular route [16]. Fig. $5 \mathrm{~b}$ shows the microstructure after annealing at $350^{\circ} \mathrm{C}$ for 24 hours. A dual grain size distribution, similar to the as-rolled initial material, was observed in the annealed microstructure. The average grain size was $\bar{d} \sim 3-4 \mu \mathrm{m}$ and $\bar{d} \sim 15 \mu \mathrm{m}$ before and after annealing, respectively. For reference, the as-received AZ31 material had $\bar{d} \sim 20 \mu \mathrm{m}$. Recall that annealing was done on the ECAE processed materials to recover the microstructure and grow the grains back to the regime of the as-received material so as to focus on texture effects only.

Figure 6 shows the evolution of texture of material $4 \mathrm{~A}$ after 2, 10, and 24 hours of annealing treatments. The location of the main poles were not significantly altered during annealing. However, the texture's strength was slightly reduced with annealing time. Furthermore, additional weak basal poles appeared along the $\mathrm{F}$ and $\mathrm{E}$ directions after annealing, which may be a consequence of annealing twins induced grains. 
The effect of annealing on the microstructure of material $4 \mathrm{C}$ is illustrated in Fig. 7. It is known that the microstructure of the as-processed material is more uniform in this route. This is indeed confirmed by Fig. 7a. The same applies to the annealed microstructure shown in Fig. 7b. For this material, the average grain sizes were $\bar{d} \sim 3-4 \mu \mathrm{m}$ and $\bar{d} \sim$ $18 \mu \mathrm{m}$ before and after annealing, respectively; compare with $\bar{d} \sim 20 \mu \mathrm{m}$ for the as-received material.

Figure 8 shows the evolution of texture after 2, 10, and 24 hours of annealing treatments, for the material processed through route $4 \mathrm{C}$. Here too the texture seems to weaken slightly without notable changes in the location of the basal and prismatic poles subsequent to annealing.

\subsection{Stress-Strain Behavior}

Details of the tensile stress-strain curves for all orientations will be shown later in the context of discussing the directionality of ductility. Here, it suffices to recall that material 4A exhibits the usual tension-compression asymmetry in all orientations whereas material 4C exhibits asymmetry when tested along the flow direction F. The other two principal directions (E and L) had negligible tension-compression asymmetry in yield but some in subsequent flow, in keeping with previously published results [16]. Typical nominal stress versus logarithmic strain responses in tension along the extrusion direction are shown in Fig. 9 for both $4 \mathrm{~A}$ and $4 \mathrm{C}$ materials and compared with the response of the as-received material loaded along the rolling direction. Initial yield strengths increase in the order 4C, 4A, as-received although the ultimate strengths are comparable (225-250 MPa). On the

othr hand, the tensile ductility decreases in that same order with material $4 \mathrm{C}$ being more ductile.

\subsection{Anisotropy Strain Ratios}

Fig. 10 shows the strain ratios in compression, measured for various loading orientations, against the plastic strain for material 4A. As described in Section 3.3.2 the evolution of the 
strain ratios was followed during compression tests through frequent test interruptions. The five ratios reported in the figure $\left(R^{\mathrm{E}}\right.$ and $R^{\mathrm{F}}$ for principal directions, $R^{\mathrm{EF}}, R^{\mathrm{FL}}$ and $R^{\mathrm{LE}}$ for off-axes directions) are those that appear in the equations of Appendix A. Furthermore, to avoid data clutter, the results are grouped in two sets. In the first, Fig. 10a, the strain ratio keeps evolving with plastic strain with no indication of a steady-state behavior. In the second set, Fig. 10b, the two ratios $R^{\mathrm{LE}}$ and $R^{\mathrm{E}}$ exhibit a steady state behavior after a transient, as discussed in [35] for as-received AZ31. These trends underscore the complex evolving plastic anisotropy in the material.

In tension, the existence of a steady state could not be ascertained because of a restricted set of measurements. The strain ratios were determined at sufficiently large strains prior to fracture. The first two columns of Table 1 summarize some relevant values for material 4A. Note that the data for the $\mathrm{L}$ orientation is missing. This is because the strain ratios need not be measured for all three principal directions, according to the procedure explained in Appendix A.

\begin{tabular}{l|cccc|cccc}
\hline & \multicolumn{4}{|c|}{ Material 4A } & \multicolumn{4}{c}{ Material 4C } \\
Load & \multicolumn{3}{|c|}{ Strain Ratio, $R^{\mathrm{X}}$} & \multicolumn{4}{c|}{ Hill Coefficient, $h_{\mathrm{X}}$} & \multicolumn{3}{c}{ Strain Ratio, $R^{\mathrm{X}}$} & \multicolumn{2}{c}{ Hill Coefficient, $h_{\mathrm{X}}$} \\
Orientation & Tension & Comp. & Tension & Comp. & Tension & Comp. & Tension & Comp. \\
\hline E & 0.60 & 5.12 & 1.19 & 0.59 & 0.55 & 0.22 & 1.25 & 1.32 \\
F & 0.59 & 1.33 & 0.88 & 1.15 & 0.35 & 0.11 & 0.79 & -0.29 \\
L & - & - & 0.37 & 2.49 & 3.34 & - & 0.20 & 1.00 \\
EF & 1.57 & 4.55 & 1.17 & 0.95 & 0.82 & 5.62 & 0.68 & 3.43 \\
FL & 3.25 & 0.23 & 2.50 & 4.28 & 0.49 & 0.28 & 0.66 & 0.52 \\
LE & 0.99 & 5.91 & 0.59 & 4.30 & 0.60 & 0.38 & 0.35 & 0.12 \\
\hline
\end{tabular}

Table 1: Anisotropy strain ratios, defined by equations (6) and (7), and Hill coefficients, computed using equations (A.1)-(A.6), for materials $4 \mathrm{~A}$ and $4 \mathrm{C}$ in both tension and compression. Compression values are given at strain levels $\sim 0.09-0.10$ at which the F specimen breaks (see Fig. 10b).

Corresponding results for material $4 \mathrm{C}$ are shown in Fig. 11. Here too, the strain ratios evolve with plastic strain and the data is grouped using the same principle as in Fig. 10. Interestingly, here the two ratios that exhibit clear steady state are $R^{\mathrm{E}}$ and $R^{\mathrm{FL}}$. The $R^{\mathrm{X}}$ values are generally greater for material 4C than for material 4A despite the more "distributed" character of the texture in 4C (see Fig. 4.) Similar measurements were made in 
tension, albeit at two strain levels only. All relevant values for material $4 \mathrm{C}$ are reported in Table 1 (columns 5 and 6). Also, for tension of 4C material all principal directions were tested, hence the value of $R^{\mathrm{L}}$ reported there.

\subsection{AED index}

Having determined the strain ratios, the Hill coefficients $h_{\mathrm{X}}$ are calculated using the equations in Appendix A. All values are reported in Table 1 for both materials. Here, near terminal values of the strain ratios were used consistently, since these were always available in tension. Next, the AED index $h$ may be calculated at any stage using equation (8). The results for near terminal values are reported in Fig. 12 for all three materials in both tension and compression. For the as-received material the data is taken from [35, 44].

A few remarks are in order based on the theory introduced in Section 2. In the as-received material, the AED index is smaller than 2, either in tension or compression. This suggests that its anisotropy is of the bad kind. By way of contrast, material 4C exhibits AED index values larger than 2 whereas material $4 \mathrm{~A}$ has the AED index $>2$ in tension but $<2$ in compression. Thus, when voids are present, it is expected that the rank ordering of tensile ductility be as follows: as-received, $4 \mathrm{~A}$, then $4 \mathrm{C}$ in increasing order. The values in compression are provided for completeness.

To examine the robustness of this order of the AED index, Fig. 13 shows its evolution with plastic strain based on the systematic investigation of the compression case. Remarkably, the AED values obey the same rank ordering as for terminal values at all stages. Presumably, the same holds for tension, as further corroborated by (i) a second measurement when available (see Section 3.3.2); (ii) the attainment of a steady value after sufficient straining in compression as well as in tension of steel and aluminum alloys in previous studies [48]. Also, the variations with plastic strain of the AED values (Fig. 13) are not as erratic as some strain-ratio values (Figs. 10 and 11). 


\subsection{Notch Ductility}

In characterizing resistance to ductile fracture, any measure of uniaxial ductility (elongation to fracture, area reduction or the logarithmic measure adopted here) should be supplemented with at least a measure of notch ductility [43]. This is because of the widely documented stress-state dependence of ductility, as partly embodied in the fundamental equation (3) via the triaxiality term. In the case of $\mathrm{Mg}$ alloys, this is further required due to recent findings by Kondori and Benzerga that (i) the notch ductility of Mg alloy AZ31 is greater than its uniaxial ductility (adopting comparable measures) [35]; and (ii) the notch ductility of WE43 alloy, on the other hand, deteriorates quite drastically with notch severity [25]. Therefore, even when uniaxial ductility is enhanced, further checks are needed for the notch ductility. Fig. 14 compares the responses of the notched bars loaded along E (or $\mathrm{R}$ for the as-received material). Clearly, the fracture strains follow the rank order suggested by the $\mathrm{AED}$ index, i.e., material $4 \mathrm{C}$ is more ductile than $4 \mathrm{~A}$, which is more ductile than the as-received alloy. The peculiar shape of the load-deflection responses is because a load cell of large capacity was used on relatively small specimens. This, however, does not alter the order of fracture strains, for example as estimated based on area reduction. While it may be argued that material 4C exhibits a softer response, the limit loads in the 4A and as-received specimens are comparable. Finally, it is worth noting that for each material the fracture strain is greater in the notched bar than it is in the smooth bar. This confirms and generalizes the trend first revealed in [35] for as-received AZ31.

\subsection{Directionality in Ductility}

While both the uniaxial and notch ductilities seem to follow the AED-based projections, it is expected that the ductility depends on loading orientation. To quantify this, Fig. 15 reports the fracture strains measured for uniaxial tension along all six orientations. To facilitate comparison, the fracture strain for a given orientation is normalized by its value for the as-received material using the identification $(E, F, L)$ to $(R, T, N)$ for orientation correspondence. With this definition, values above unity indicate an increase in ductility with 
respect to the as-received alloy for a given loading direction. For the three off-axis orientations, the fracture strain was normalized by that of the 4A material because the data was not available for the as-received material used in this study.

What is plotted in Fig. 15a is the strain to failure initiation, that is at the load drop in the global response after passing the ultimate tensile strength point. The latter is shown for all loading orientations in Fig. 16. By way of variation, Fig. 15b reports the strain to complete rupture, as inferred from area reduction measurements post-mortem. The ductility of all materials was found to be orientation dependent. Data points match for the as-received material, as a result of normalization. The trends are insensitive to the measure used (Fig. 15a versus Fig. 15b). It is clear that ductility is enhanced in all directions after ECAE and postECAE annealing, even if the increase is modest in some orientations. Not only this figure establishes a correlation between the AED index and ductility, irrespective of orientation, it also shows a $70 \%$ increase in ductility in certain orientations.

\subsection{Fracture Mechanisms}

The fracture surfaces of notched specimens of ECAE 4A and 4C materials both exhibit a dimpled character, Fig. 17. Initially smooth flat tensile specimens also exhibited some isolated regions with dimples for some loading orientations. However, longitudinal cuts (not shown) invariably show shear rupture, even if only partial. This is consistent with the findings in [35] for as-received AZ31. The dimpled character of fracture surfaces in notched specimens is clear indication that the well established cavitation processes are active in both materials. Zooming into the fractographs, second-phase particles may be observed in many dimples (see Fig. 17b and e) suggesting that some significant damage occurred due to void nucleation at these particles and subsequent growth to coalescence.

In order to gain further insight into the damage mechanisms, longitudinal sections of broken bars were prepared (see Section 3.4). They are shown in Fig. 18. Interestingly, sections in E-L planes (Fig. 18a and b) show slightly slant fracture surfaces. Higher resolution observations (not shown) do not show extensive damage sites in such sections. On the 
other hand, longitudinal sections in E-F planes where the crack path is macroscopically flat (as opposed to slant) reveal extensive damage beneath the surface. An example is shown in Fig. $18 \mathrm{c}$ in the case of $4 \mathrm{C}$ material. Fig. 19 illustrates some close-ups of individual damage sites in Fig. 18c. The various stages of void formation at second-phase particles, void enlargement and coalescence can be observed.

It appears therefore that damage develops in some rather anisotropic fashion. Although not fully investigated here, this sequence of events was studied in some detail by Kondori [44] in as-received AZ31. He showed that the above evidenced processes of cavitation lead to formation of larger blunted cracks which run parallel to one principal direction (here the flow direction F). As there are multiple such macrocracks in the specimen they link up by shear localization and shear rupture. This may explain the slanting observed in E-L sections or the macro-splits observed directly onto fracture surfaces of Fig. 17a and d.

Fig. 20 shows some high-resolution SEM images of damage nucleation sites, here mainly second-phase particles. Analysis by EDS reveals that the particles are Al-Mn rich. The dominant nucleation mechanism is by particle cracking, although lower-resolution images may suggest decohesion at the poles.

To sum up, the fractography analyses reveal that cavitation processes are active in both processed materials. Cavitation occurs at Al-Mn second-phase particles, mostly by cracking. Also, this cavitation extends far beyond the fracture surface and may not be evident in all planes of view.

\section{Discussion}

The advocated concept of designing anisotropy for ductility enhancement is general. One may question the choice of $\mathrm{Mg}$ alloys to develop a proof-of-concept, given their complex behavior. A high stacking fault energy, face-centered cubic material would be an alternative choice as it would alleviate complications associated with twinning and tensioncompression asymmetry. However, among all technologically relevant materials, Mg al- 
loys are those about which plastic anisotropy is most commonly invoked as a hinderance to ductility. Therefore, if verified, the AED concept is most potent in their context. In addition, the chosen material system must be such that wide variations in plastic anisotropy are possible so that anisotropy-ductility correlations are unequivocal. Clearly, this trait is facilitated in a material with a strong inherent, crystal-level anisotropy such as Mg. Finally, void growth is affected by remote tension, so that tension-compression asymmetry plays a secondary role.

In the Mg literature, the phrase "texture engineering" is invoked to mean, nearly systematically, reducing, weakening or randomizing the texture altogether [2] in order to minimize the anisotropy. Such engineering is predicated on the premise that the strong texture of wrought $\mathrm{Mg}$ alloys is deleterious to fracture resistance. The work initiated here aims at shifting the design paradigm toward engineering, not suppressing, the anisotropy of wrought metallic materials, in particular Mg alloys, for example via their texture. The rationale for this is two-fold: the lack of success in demonstrating that the more isotropic $\mathrm{Mg}$ alloys are considerably more ductile at ambient temperature; and a hypothesis based on mechanistic understanding of ductile damage.

Over the past decade, significant efforts have been devoted to texture weakening in $\mathrm{Mg}$ alloys, notably by addition of RE elements; for a review see [2]. In the most successful realizations of this concept, the following attributes have clearly been demonstrated: (i) up-to-random levels of texture, with recrystallization playing a key role; (ii) no tensioncompression asymmetry (on strength); (iii) finer grains, hence higher strength; and (iv) solute segregation to grain boundaries as a key solute-related mechanism that retards recrystallization. Many studies also claim that the ductility is improved in RE alloys. Fair examination of the results, including for WE43 alloy [21-24], shows however that the ductility is at best the same as in commercially available alloys such as AZ31. The mere fact that ductility levels of AZ31 have barely been retained indicates that anisotropy-ductility correlations are more complex than widely reported. The situation is in fact worse. In a recent study, two of the authors have shown that the notch ductility of WE43 Mg alloy, 
with RE elements, is poor in comparison with that of AZ31 [25].

The work undertaken here is hypothesis driven. The hypothesis, which emanates from the theory of void growth in anisotropic plasticity, may be restated as follows: plastic anisotropy affects ductility to first order and this effect may be captured by the AED index. If confirmed, the hypothesis could enable to make projections regarding ductility levels on the sole basis of plastic anisotropy measurements, and by way of consequence, establish a new design paradigm whereby material attributes responsible for the anisotropy, such as texture, may be reverse engineered to obtain desired values of AED indices. Evidently, such reverse engineering would require a suite of other experimental and modeling tools to be established.

In this paper, focus has been laid on testing the validity of the said hypothesis. In order to do so, several materials sharing the same chemical composition and average grain size, but possessing different levels of plastic anisotropy had to be prepared. In addition, cavitation had to be established as the main damage mechanism (otherwise, the correlation in Fig. 15 which is in keeping with the hypothesis, would be fortuitous). Then, establishing a correlation between plastic anisotropy and ductility required that measurements of both be carried out. Several ways and definitions of each are possible. In the literarture, both plastic anisotropy and ductility of $\mathrm{Mg}$ alloys are poorly characterized. The anisotropy is often reported in terms of r-values for sheet metals, or in terms of loadings along principal directions, whereas the ductility is often reported for initially smooth bars. For plastic anisotropy, what is important is that the full 3D anisotropy had to be characterized. Indeed, the AED index involves contributions from all six anisotropy coefficients (the $h_{i}$ ) with the shear coefficients having more weight; see equation (4). For ductility, it was important to verify not only the directionality but also the stress state dependence, i.e. notch ductility in addition to uniaxial ductility (recall that the latter is comparable between AZ31 and WE43 alloys whereas the former is much better in AZ31 [25]). When all such measurements were completed the correlation between a measure of plastic anisotropy (AED index) and several measures of ductility (tensile as well as notch tension) was established. 
The AED index is a powerful indicator because it results from micromechanics and homogenization theory. As such, it does not account however for local, crystallographic aspects of void growth, e.g. faceted growth, interaction with twins, etc. These effects may be important but, at present, there are no simple design-friendly factors, such as the AED index, to capture them.

Also, it bears emphasis that in the equations of the theory texture does not enter explicitly. Whatever causes plastic anisotropy at a scale relevant to void growth is expected to affect the rate of growth. In this work, we have taken advantage of the possibility to alter textures to affect the plastic anisotropy, but more generally, any microstructural effect that can lead to variations in the overall anisotropy could be manipulated. In particular, the theory does account for twinning and other crystallographic aspects, albeit at a coarse scale, to the extent that such aspects impart the plastic flow with some net anisotropy.

\section{Conclusions}

Experimental work has been undertaken to test the hypothesis that plastic anisotropy affects the ductility of materials, irrespective of loading orientation and stress state. The hypothesis is based on the theory of void growth in plastically anisotropic materials. Here, it has been tested in the context of technologically important Mg alloys using severe plastic deformation as a means to generate various texture-induced levels of plastic anisotropy. Our findings are as follows:

- The hypothesis was verified. A simple scalar measure termed the anisotropy-effecton-ductility (AED) index was introduced which is based on 3D measurements of plastic strain ratios. Materials with an AED index above 2 are expected to be significantly more ductile than their isotropic counterparts, at fixed chemical composition and grain size, provided that shear failure is avoided.

- Unprecedented measurements of 3D plastic anisotropy were reported which can serve as basis for critical assessment of advanced constitutive models for Mg alloys. 
Some of the strain ratios exhibit large unsteady variations upon plastic straining. However, the AED index remarkably shows a more steady evolution.

- The approach followed here aimed at testing a hypothesis; in that sense it tackled the forward problem of establishing the correlation between anisotropy and ductility. More experiments are needed on other materials to confirm the trends established here. For such an approach to reach its full potential, the inverse problem in materials design should also be tackled, that is: given a desired AED index what modeling tools and associated validation experimental methods are most appropriate to design the plastic anisotropy, through texture manipulation or otherwise? The success of the approach opens the door for a paradigm shift in thinking about the use of plastically anisotropic materials in structural applications.

\section{Acknowledgments}

This research was supported by the National Science Foundation (CMMI Award No. 1563580). Initial support from the Qatar National Research Fund (a member of Qatar Foundation) under NPRP Grant No 4-1411-2-555 and NSF Award DMR-0844082 is gratefully acknowledged.

\section{References}

[1] S. R. Agnew, J. F. Nie, Preface to the viewpoint set on: The current state of magnesium alloy science and technology, Scripta Materialia 63 (2010) 671-673.

[2] J. Hirsch, T. Al-Samman, Superior light metals by texture engineering: optimized aluminum and magnesium alloys for automotive applications, Acta Materialia 61 (2013) 818-843.

[3] S. R. Agnew, O. Duygulu, Plastic anisotropy and the role of non-basal slip in magnesium alloy AZ31B, International Journal of Plasticity 21 (2005) 1161-1193. 
[4] M. R. Barnett, Z. Keshavarz, A. G. Beer, D. Atwell, Influence of grain size on the compressive deformation of wrought Mg-3Al-1Zn, Acta Materialia 52 (2004) 50935103.

[5] W. B. Hutchinson, M. R. Barnett, Effective values of critical resolved shear stress for slip in polycrystalline magnesium and other hcp metals, Scripta Materialia 63 (2010) $737-740$.

[6] G. I. Taylor, Plastic strain in metals, J. Inst. Metals 62 (1938) 307.

[7] J. Koike, Enhanced deformation mechanisms by anisotropic plasticity in polycrystalline $\mathrm{Mg}$ alloys at room temperature, Metallurgical and Materials Transactions A. 36A (2005) 1689-1696.

[8] L. Remy, A. Pineau, Twinning and strain-induced F.C.C.-H.C.P. transformation in the FeMnCrC system, Materials Science and Engineering 28 (1977) 99-107.

[9] J. W. Christian, S. Mahajan, Deformation twinning, Progress in Materials Science 39 (1995) 1-157.

[10] M. H. Yoo, Slip, twinning, and fracture in hexagonal close-packed metals, Metallurgical Transactions 12 (1981) 409-418.

[11] E. Dogan, M. W. Vaughan, S. Wang, I. Karaman, G. Proust, Role of Starting Texture and Deformation Modes on Low Temperature Shear Formability and Shear Localization of Mg-3Al-1Zn Alloy, Acta Materialia 89 (2015) 408-422.

[12] J. Koike, T. Kobayashi, T. Mukai, H. Watanabe, M. Suzuki, K. Maruyama, K. Higashi, The activity of non-basal slip systems and dynamic recovery at room temperature in fine-grained AZ31B magnesium alloys, Acta Materialia 51 (2003) 2055-2065.

[13] S. B. Yi, C. H. J. Davies, H. G. Brokmeier, R. E. Bolmaro, K. U. Kainer, J. Homeyer, Deformation and texture evolution in AZ31 magnesium alloy during uniaxial loading, Acta Materialia 54 (2006) 549-562. 
[14] X. Gao, J. F. Nie, Characterization of strengthening precipitate phases in a Mg-Zn alloy, Scripta Materialia 56 (2007) 645-648.

[15] L. Capolungo, I. J. Beyerlein, C. N. Tome, Slip-assisted twin growth in hexagonal close-packed metals, Scripta Materialia 60 (2009) 32-35.

[16] M. Al-Maharbi, I. Karaman, I. J. Beyerlein, D. Foley, K. T. Hartwig, L. J. Kecskes, S. N. Mathaudhu, Microstructure, crystallographic texture, and plastic anisotropy evolution in an $\mathrm{Mg}$ alloy during equal channel angular extrusion processing, Materials Science and Engineering:A 528 (2011) 7616-7627.

[17] E. A. Ball, P. B. Prangnell, Tensile-compressive yield asymmetries in high-strength wrought magnesium alloys, Scripta Materialia 31 (1994) 111-116.

[18] N. Stanford, M. Barnett, The origin of rare earth texture development in extruded mgbased alloys and its effect on tensile ductility, Materials Science and Engineering: A 496 (2008) 399-408.

[19] J. Bohlen, M. R. Nuernberg, J. W. Senn, D. Letzig, S. R. Agnew, The texture and anisotropy of magnesium-zinc-rare earth alloy sheets, Acta Materialia 55 (2007) 2101-2112.

[20] K. Hantzsche, J. Bohlen, J. Wendt, K. U. Kainer, S. B. Yi, D. Letzig, Effect of rare earth additions on microstructure and texture development of magnesium alloy sheets, Scripta Materialia 63 (2010) 725-730.

[21] S. Sandloebes, S. Zaefferer, I. Schestakow, S. Yi, R. Gonzalez-Martinez, On the role of non-basal deformation mechanisms for the ductility of Mg and Mg-Y alloys, Acta Materialia 59 (2011) 429-439.

[22] S. Sandloebes, Z. Pei, M. Friak, L.-F. Zhu, F. Wang, S. Zaefferer, D. Raabe, J. Neugebauer, Ductility improvement of Mg alloys by solid solution: Ab initio modeling, synthesis and mechanical properties, Acta Materialia 70 (2014) 92-104. 
[23] N. Kumar, N. Dendge, R. Banerjee, R. Mishra, Effect of microstructure on the uniaxial tensile deformation behavior of $\mathrm{mg}-4 \mathrm{y}-3 \mathrm{re}$ alloy, Materials Science and Engineering:A 590 (2014) 116-131.

[24] Z. Leng, J. Zhang, J. Sun, H. Shi, S. Liu, L. Zhang, M. Zhang, R. Wu, Notch tensile behavior of extruded $\mathrm{Mg}-\mathrm{Y}-\mathrm{Zn}$ alloys containing long period stacking ordered phase, Materials \& Design 600 (2014) 495-499.

[25] B. Kondori, A. A. Benzerga, On the notch ductility of a magnesium-rare earth alloy, Materials Science and Engineering:A 647 (2015) 74-83.

[26] V. M. Segal, Severe plastic deformation: simple shear versus pure shear, Materials Science and Engineering:A 338 (2002) 331-344.

[27] R. Z. Valiev, T. G. Langdon, Principles of equal-channel angular pressing as a processing tool for grain refinement, Progress in Materials Science 51 (2006) 881-981.

[28] T. Mukai, M. Yamanoi, H. Watanabe, K. Higashi, Ductility enhancement in AZ31 magnesium alloy by controlling its grain structure, Scripta Materialia 45 (2001) 8994.

[29] S. Agnew, J. Horton, T. Lillo, D. Brown, Enhanced ductility in strongly textured magnesium produced by equal channel angular processing, Scripta Materialia 50 (2004) 377-381.

[30] D. C. Foley, M. Al-Maharbi, K. T. Hartwig, I. Karaman, L. J. Kecskes, S. N. Mathaudhu, Grain refinement vs. crystallographic texture: Mechanical anisotropy in a magnesium alloy, Scripta Materialia 64 (2011) 193-196.

[31] S. M. Razavi, D. C. Foley, I. Karaman, K. T. Hartwig, O. Duygulu, L. J. Kecskes, S. N. Mathaudhu, V. H. Hammond, Effect of grain size on prismatic slip in $\mathrm{Mg}-3 \mathrm{Al}-1 \mathrm{Zn}$ alloy, Scripta Materialia 67 (2012) 439-442. 
[32] E. Dogan, I. Karaman, G. Ayoub, G. Kridli, Reduction in Tension-Compression Asymmetry via Grain Refinement and Texture Design in Mg-3Al-1Zn Sheets, Materials Science and Engineering 610 (2014) 220-227.

[33] A. A. Benzerga, J.-B. Leblond, Ductile fracture by void growth to coalescence, Advances in Applied Mechanics 44 (2010) 169-305.

[34] A. Benzerga, J. Besson, Plastic potentials for anisotropic porous solids, European Journal of Mechanics 20 (2001) 397-434.

[35] B. Kondori, A. A. Benzerga, Effect of Stress Triaxiality on the Flow and Fracture of Mg Alloy AZ31, Metallurgical and Materials Transactions A. 45 (2014) 3292-3307.

[36] A. A. Benzerga, J. Besson, A. Pineau, Modèle couplé comportementendommagement ductile de tôles anisotropes, in: B. Peseux, D. Aubry, J. P. Pelle, M. Touratier (Eds.), Actes du 3 ème Colloque National en Calcul des Structures, Presses Académiques de l'Ouest, 1997, pp. 673-678.

[37] S. M. Keralavarma, A. A. Benzerga, An approximate yield criterion for anisotropic porous media, Comptes Rendus Mecanique 336 (2008) 685-692.

[38] S. M. Keralavarma, A. A. Benzerga, A constitutive model for plastically anisotropic solids with non-spherical voids, Journal of the Mechanics and Physics of Solids 58 (2010) 874-901.

[39] J. B. Stewart, O. Cazacu, Analytical yield criterion for an anisotropic material containing spherical voids and exhibiting tension-compression asymmetry, International Journal of Solids and Structures 48 (2011) 357-373.

[40] S. M. Keralavarma, A. A. Benzerga, Numerical assessment of an anisotropic porous metal plasticity model, Mechanics of Materials 90 (2015) 212-228.

[41] R. Hill, A theory of yielding and plastic flow of anisotropic solids, Proceedings of the Royal Society of London A 193 (1948) 281-297. 
[42] A. A. Benzerga, Rupture ductile des tôles anisotropes, Ph.D. thesis, Ecole Nationale Supérieure des Mines de Paris, 2000.

[43] A. Pineau, A. A. Benzerga, T. Pardoen, Failure of metals I. Brittle and Ductile Fracture, Acta Materialia 107 (2016) 424-483.

[44] B. Kondori, Ductile fracture of Magnesium alloys: characterization and modeling, Ph.D. thesis, Texas A\&M University, USA, 2015.

[45] V. Herrera-Solaz, J. LLorca, E. Dogan, I. Karaman, J. Segurado, An inverse optimization strategy to determine single crystal mechanical behavior from polycrystal tests: Application to AZ31 Mg alloy, International Journal of Plasticity 57 (2014) 1-15.

[46] D. Steglich, X. Tian, J. Besson, Mechanism-based modelling of plastic deformation in magnesium alloys, European Journal of Mechanics 55 (2016) 289-303.

[47] B. Selvarajou, B. Kondori, A. A. Benzerga, S. P. Joshi, On Plastic Flow in Notched Hexagonal Close Packed Single Crystals, Journal of the Mechanics and Physics of Solids 94 (2016) 273-297.

[48] A. A. Benzerga, J. Besson, A. Pineau, Anisotropic ductile fracture. Part I: experiments, Acta Materialia 52 (2004) 4623-4638.

[49] A. A. Benzerga, J. Besson, A. Pineau, Anisotropic ductile fracture. Part II: theory, Acta Materialia 52 (2004) 4639-4650.

[50] S. Basu, A. A. Benzerga, On the path-dependence of the fracture locus in ductile materials: Experiments, International Journal of Solids and Structures 71 (2015) 79_ 90.

[51] A. K. Rodriguez, G. A. Ayoub, B. Mansoor, A. A. Benzerga, Effect of strain rate and temperature on fracture of AZ31B magnesium alloy, Acta Materialia 112 (2016) 194-208. 
[52] I. J. Beyerlein, L. S. Tóth, Texture evolution in equal-channel angular extrusion, Progress in Materials Science 54 (2009) 427-510. 

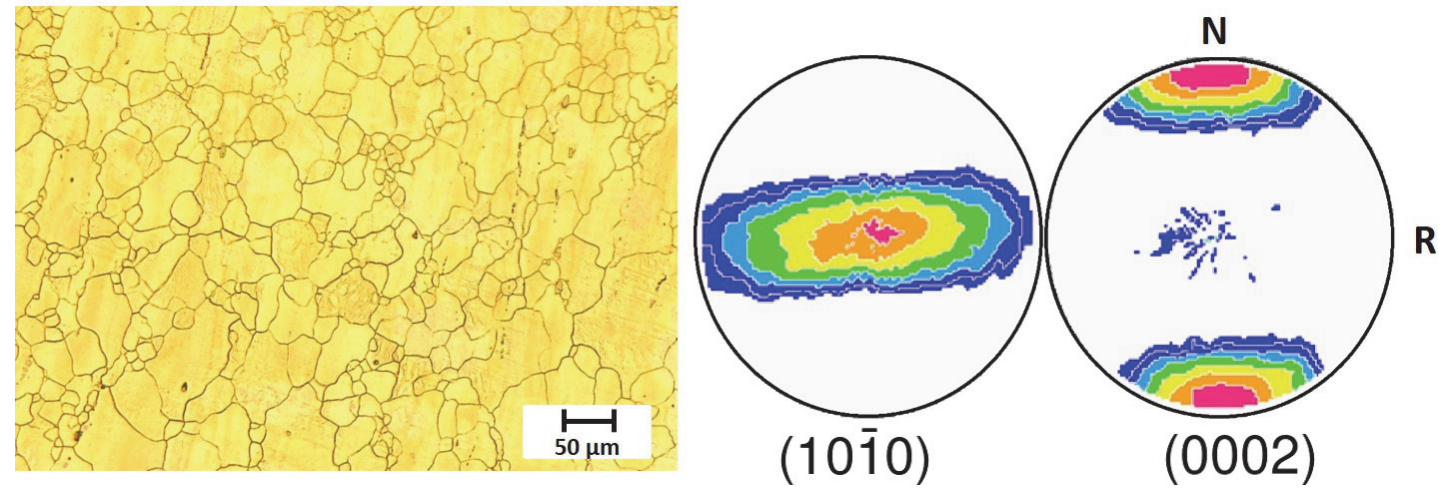

Figure 1: As-rolled microstructure and texture of a hot rolled AZ31B Mg plate. 

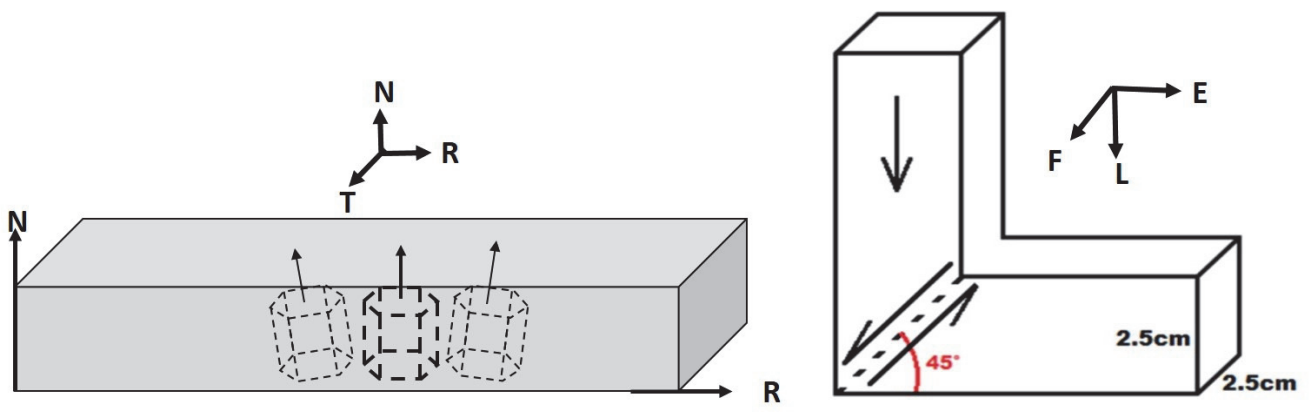

Figure 2: Schematic of (a) the as-received plate and associated directions, and (b) the die geometry used for performing ECAE through a $90^{\circ}$ corner and the directions associated with a typical billet after processing. 


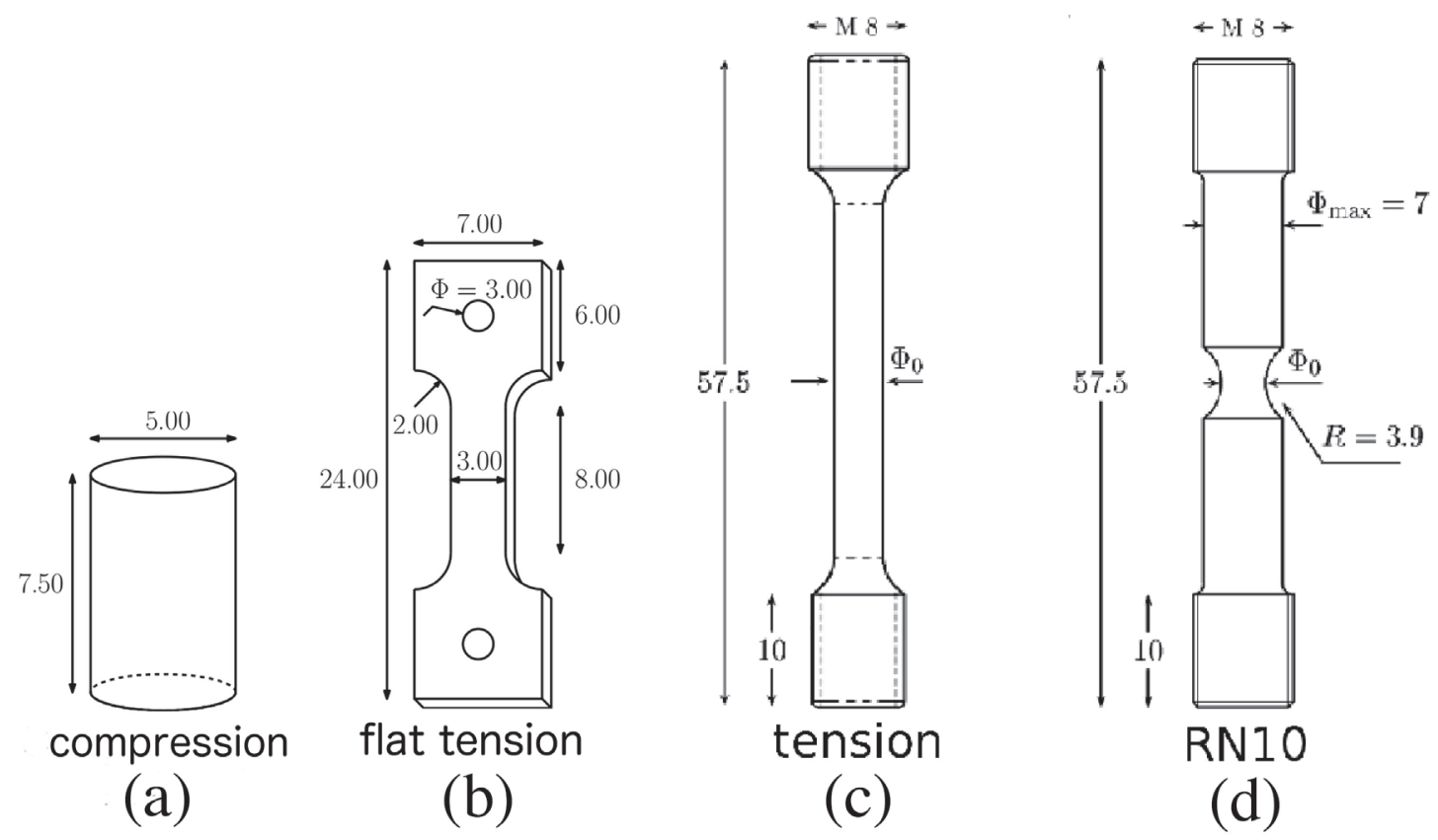

Figure 3: Geometry of the specimens used for this study. (a) Compression pins; (b) Flat tensile specimens; (c) Round tensile bars; (d) Round notched bars. 


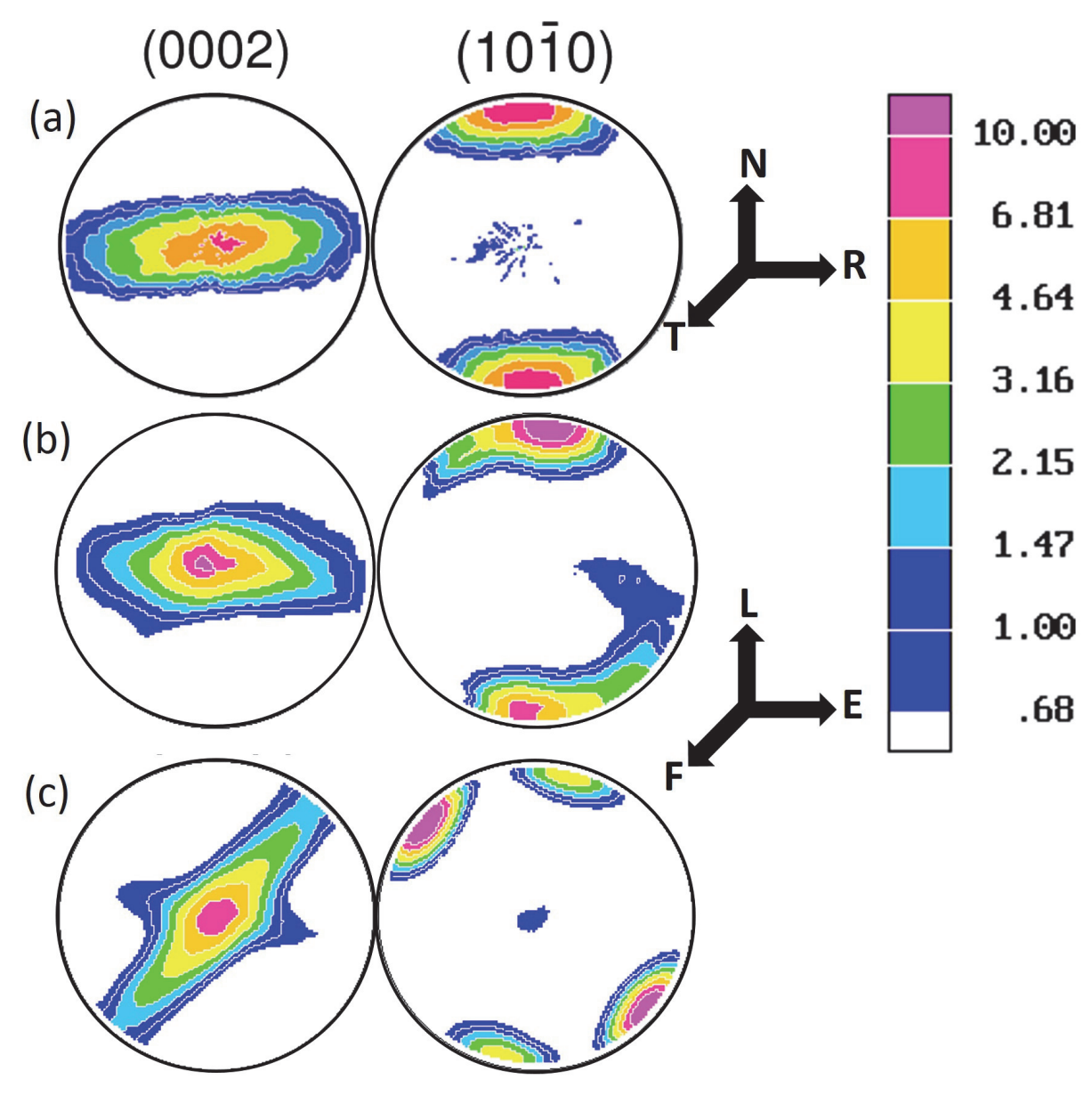

Figure 4: (1010)(left) and (0002)(right) pole figures of the Mg alloy AZ31B generated by: (a) rolling above $250^{\circ} \mathrm{C}$; (b) ECAE route $4 \mathrm{~A}$ processing at $200^{\circ} \mathrm{C}$; (c) ECAE route $4 \mathrm{C}$ processing at $200^{\circ} \mathrm{C}$. 

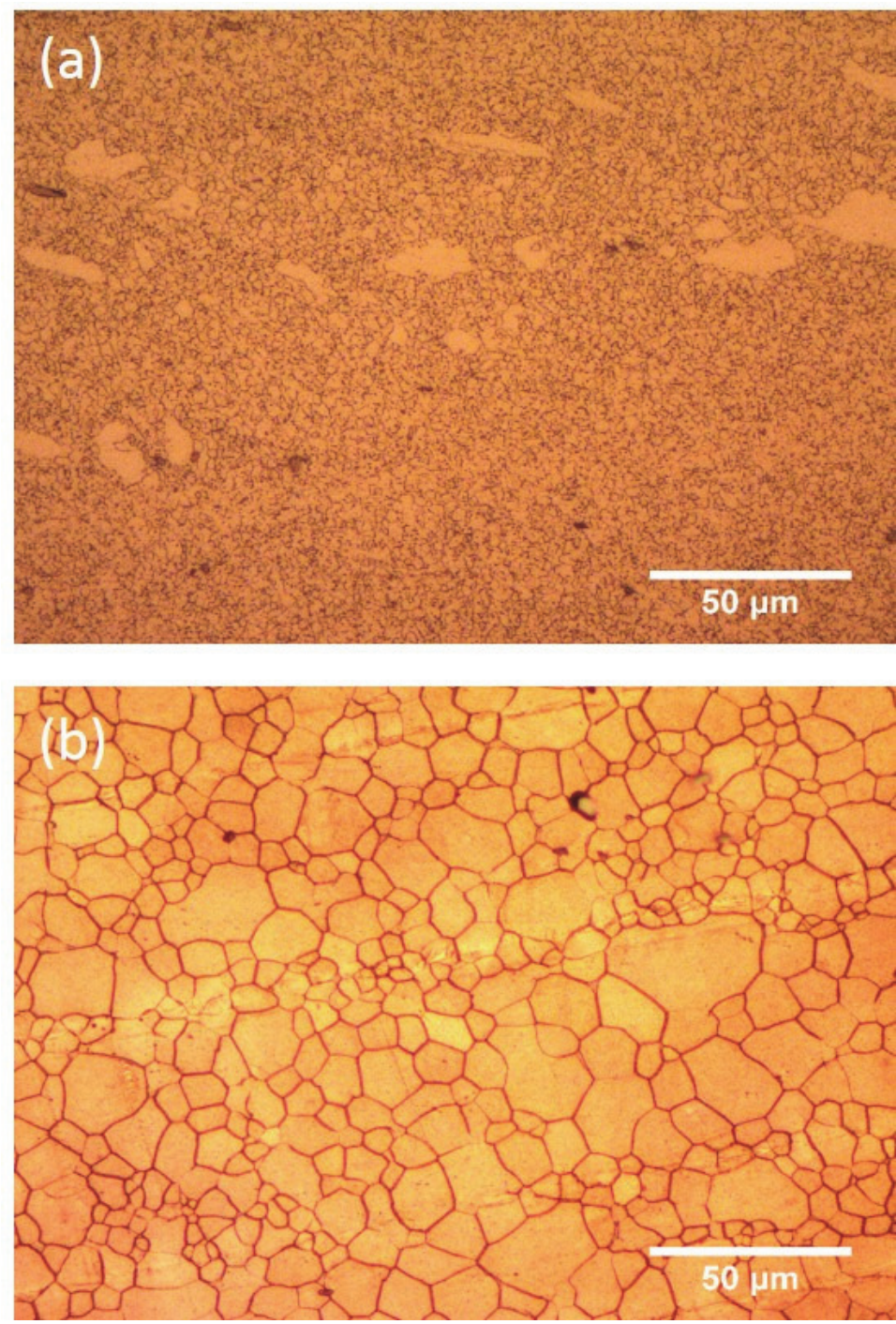

Figure 5: Microstructure of (a) as-processed 4A material, and (b) after annealing for 24 hours at $350^{\circ} \mathrm{C}$. 


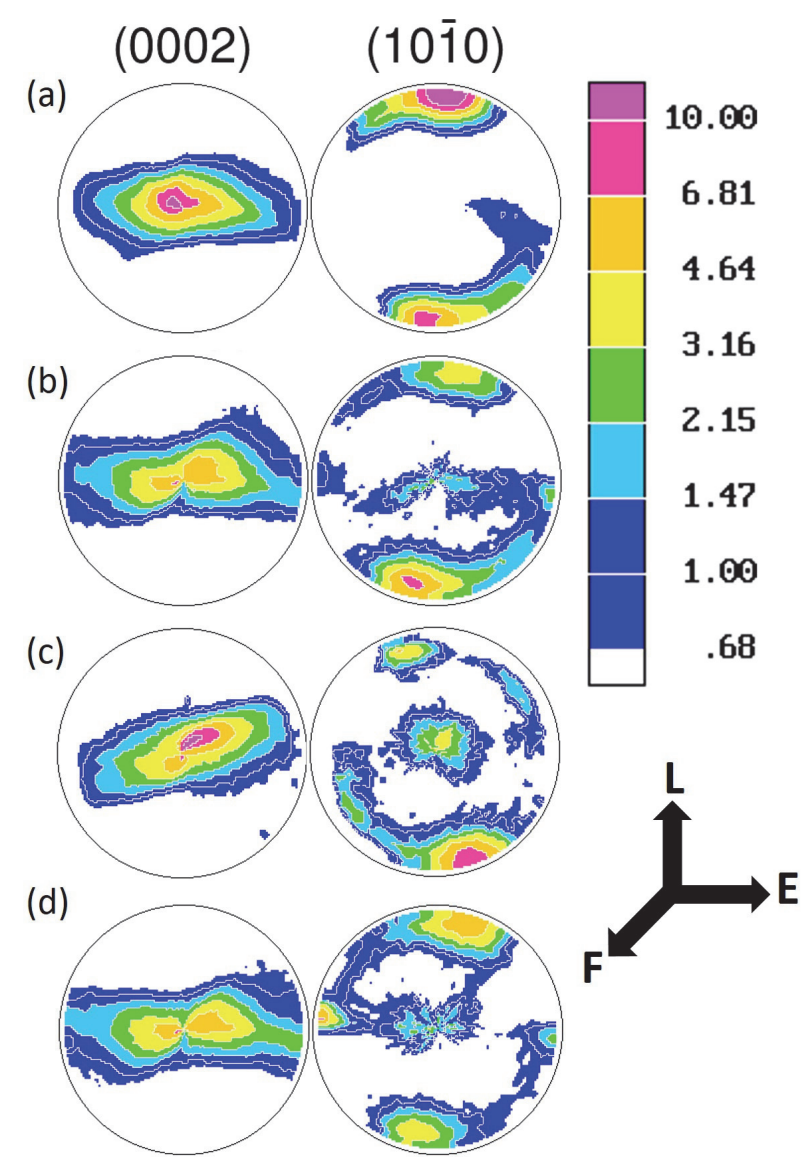

Figure 6: Texture evolution during annealing at $350^{\circ} \mathrm{C}$ for material $4 \mathrm{~A}$ at various stages (a) initial (b) 2 hours (c) 10 hours (d) 24 hours. 

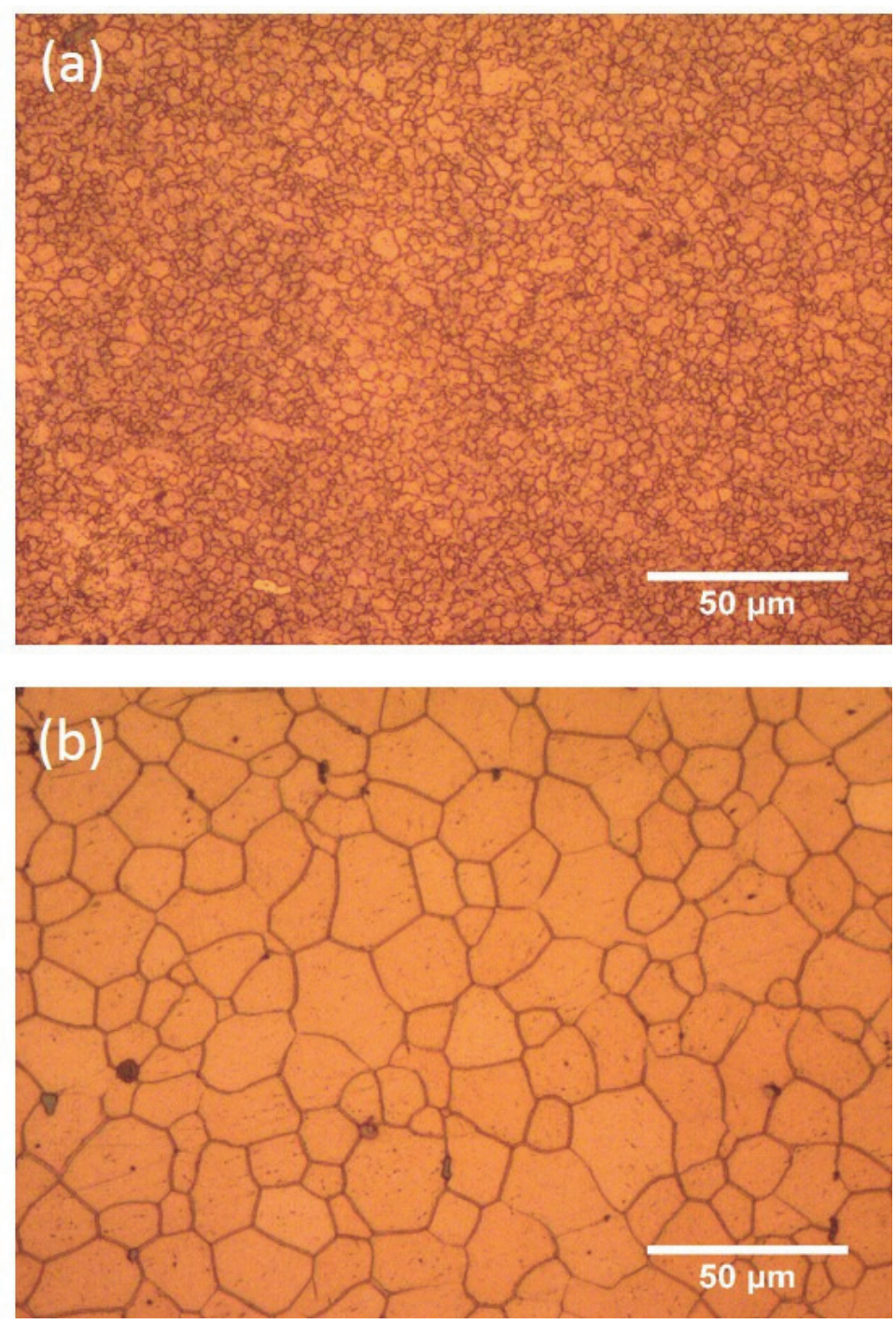

Figure 7: Microstructure of (a) as-processed 4C material, and (b) after annealing for 24 hours at $350^{\circ} \mathrm{C}$. 


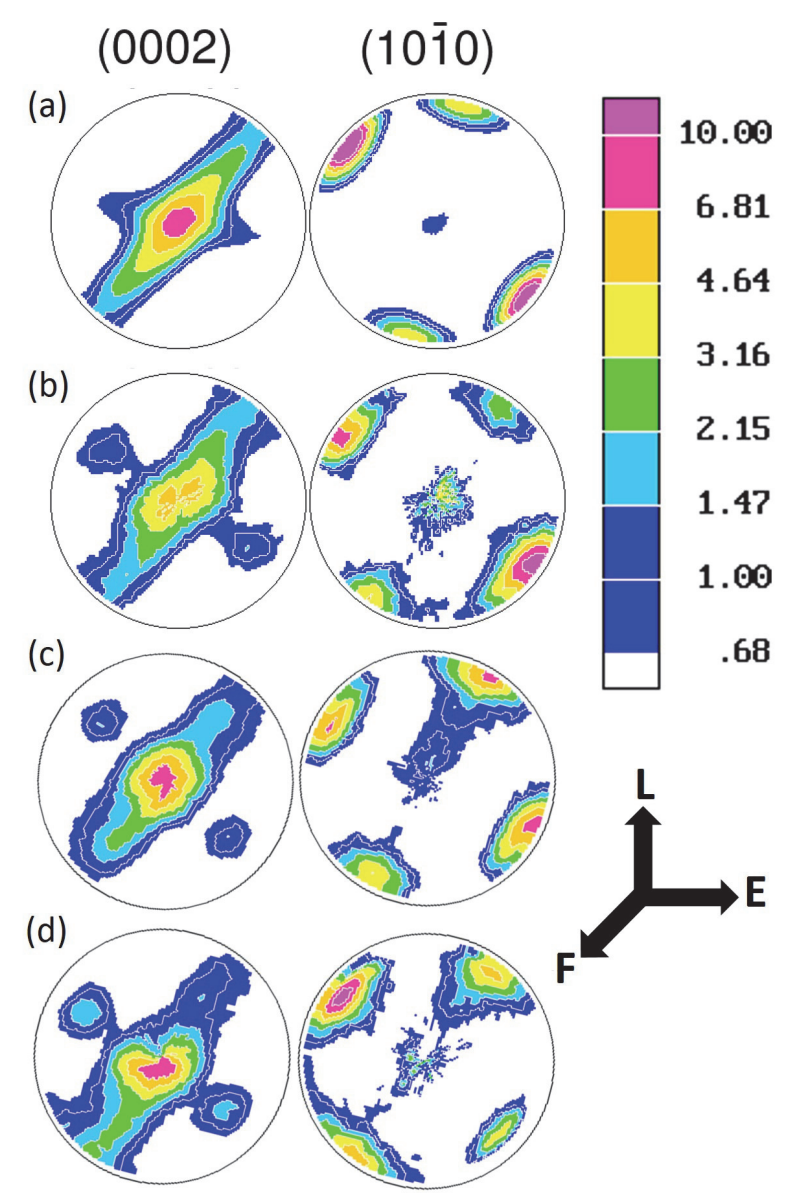

Figure 8: Texture evolution during annealing at $350^{\circ} \mathrm{C}$ for material $4 \mathrm{C}$ at various stages (a) initial (b) 2 hours (c) 10 hours (d) 24 hours. 


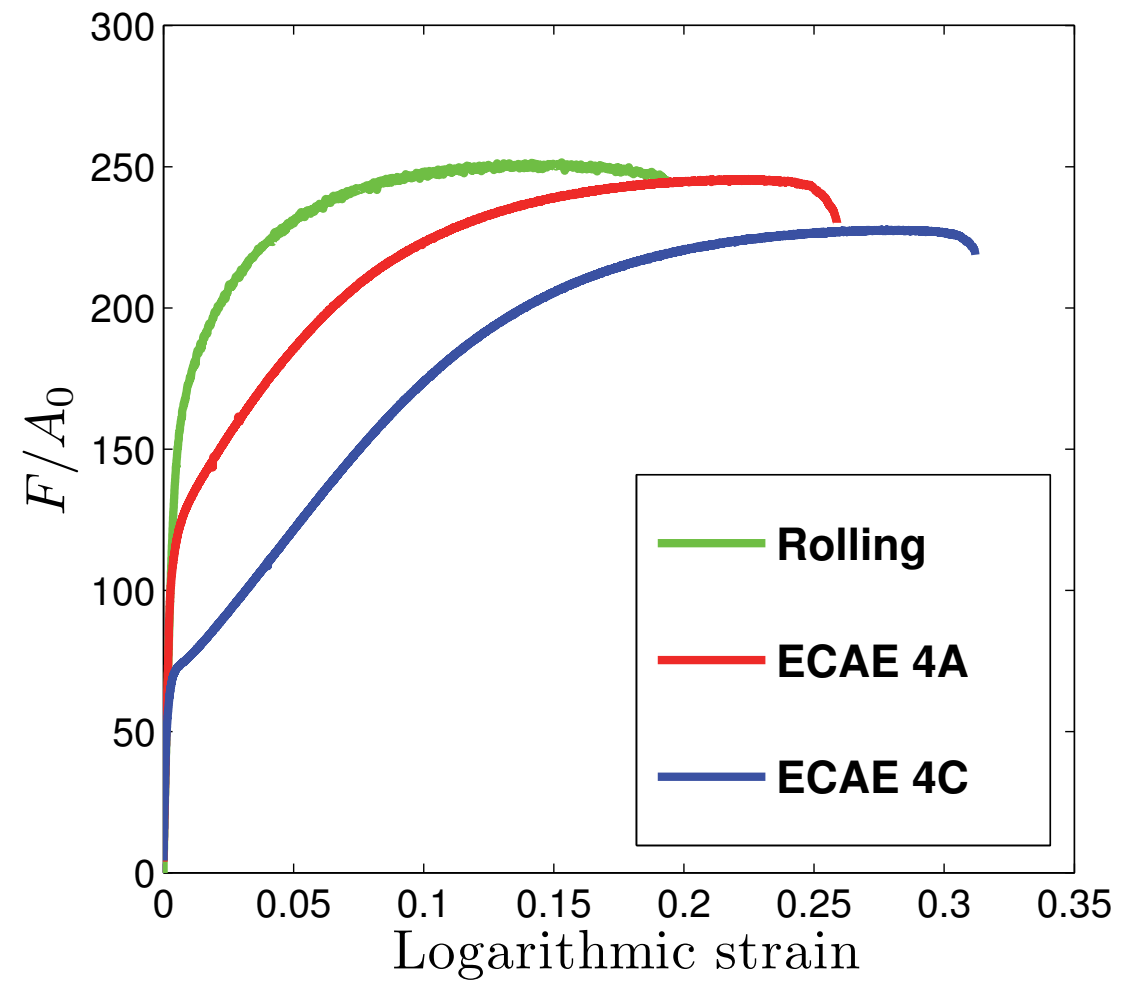

Figure 9: Nominal stress versus logarithmic strain responses in tension along the extrusion direction for 4A and $4 \mathrm{C}$ materials (after annealing) compared with the as-received material tested along the rolling direction. 


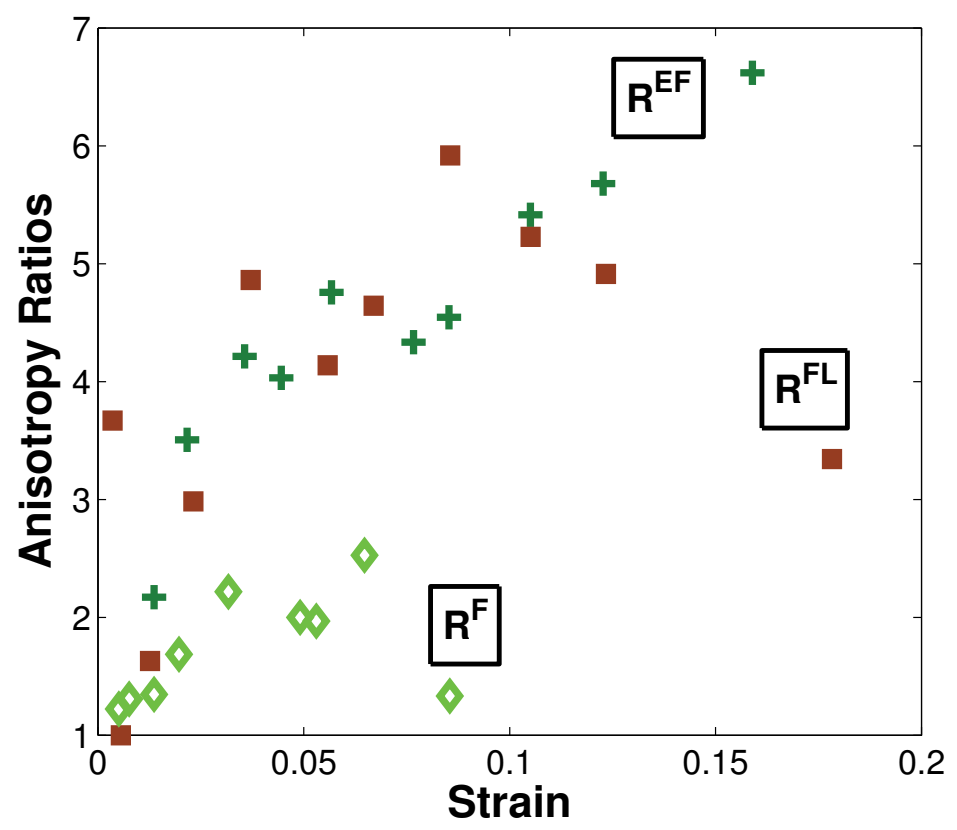

(a)

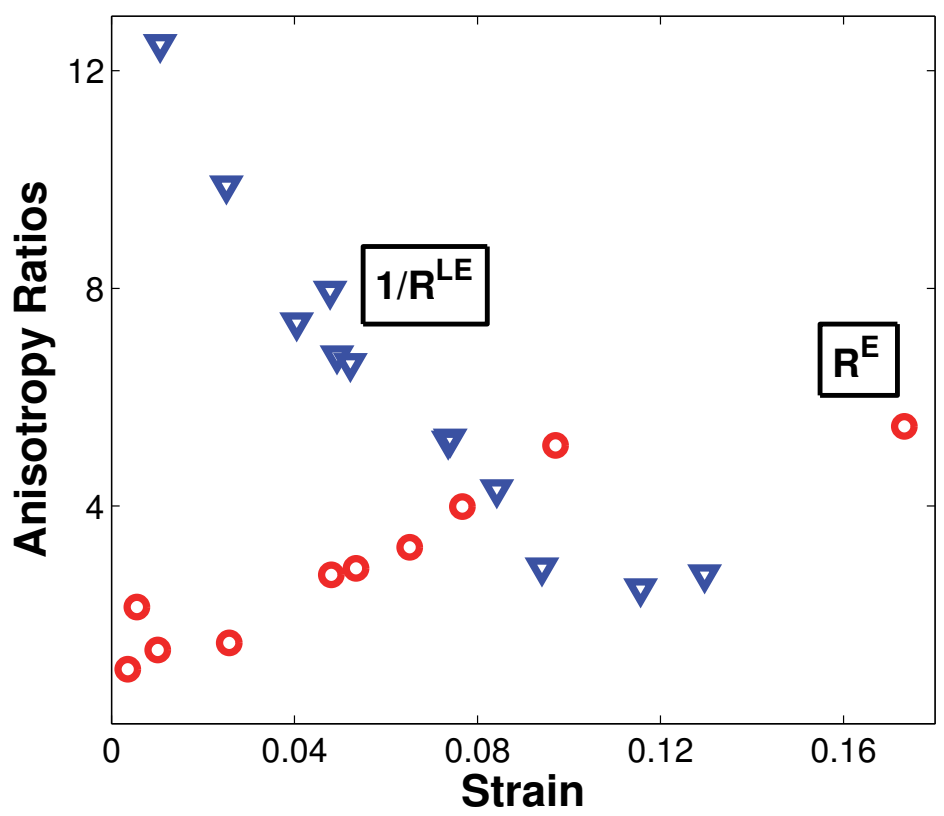

(b)

Figure 10: Anisotropy strain ratios, defined by equations (6) and (7), at various compression strain levels for material 4A and: (a) loading orientations that did not reach a steady state, and (b) orientations where the strain ratios reached a steady state. For clarity, $1 / R^{\mathrm{X}}$ is plotted instead of $R^{\mathrm{X}}$ when the latter is smaller than 1. 


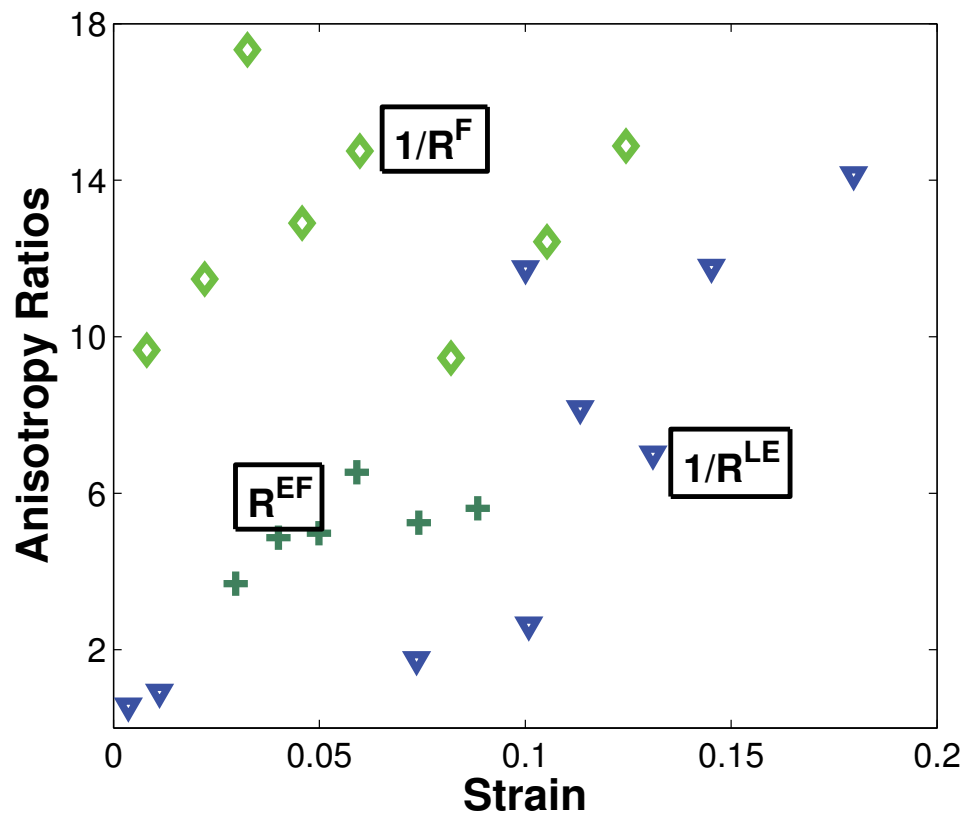

(a)

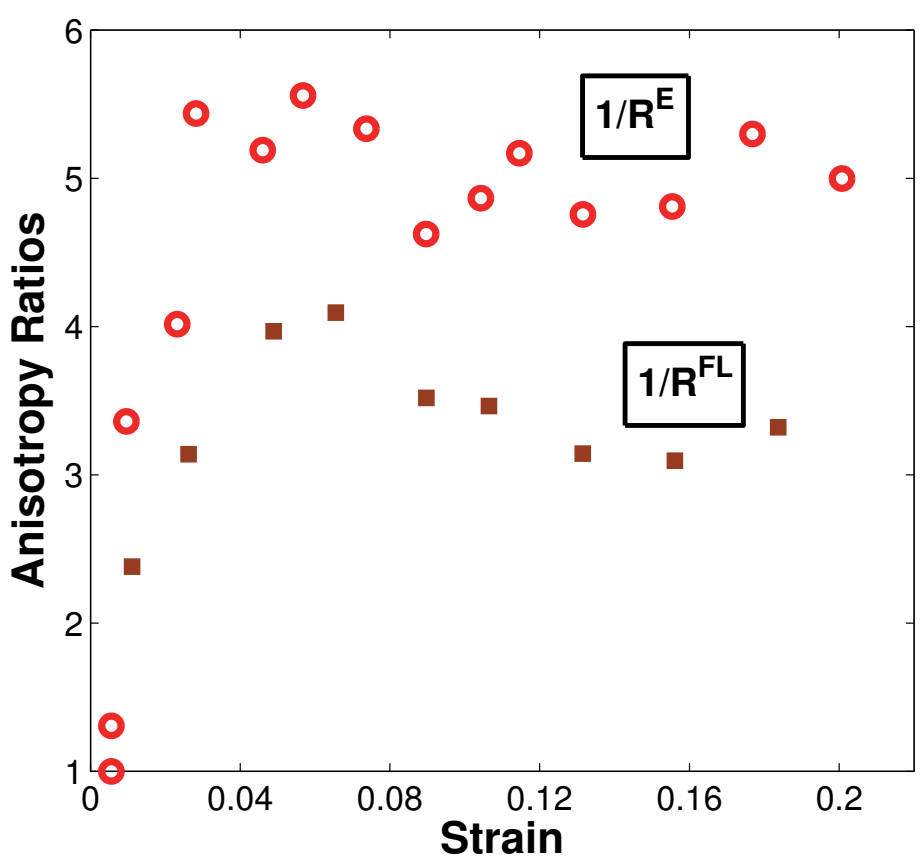

(b)

Figure 11: Anisotropy strain ratios, defined by equations (6) and (7), at various compression strain levels for material $4 \mathrm{C}$ and: (a) loading orientations that did not reach a steady state, and (b) orientations where the strain ratios reached a steady state. For clarity, $1 / R^{\mathrm{X}}$ is plotted instead of $R^{\mathrm{X}}$ when the latter is smaller than 1. 


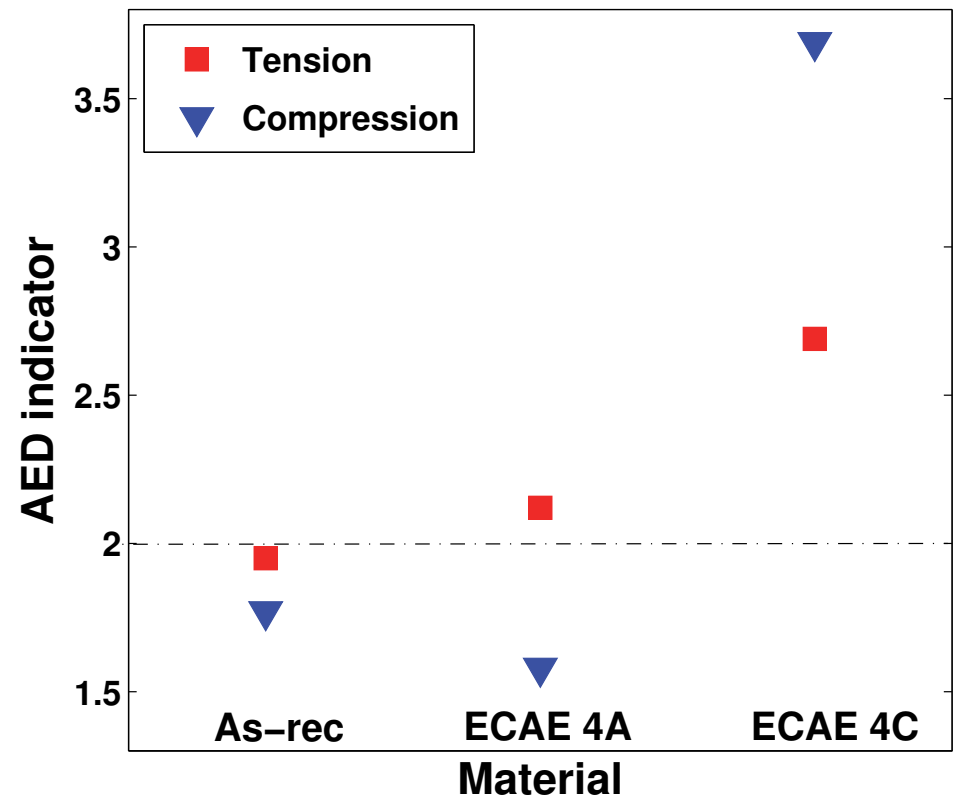

Figure 12: Anisotropy effect on ductility (AED) index in compression and tension for as-received AZ31B, ECAE 4A and ECAE 4C materials. 


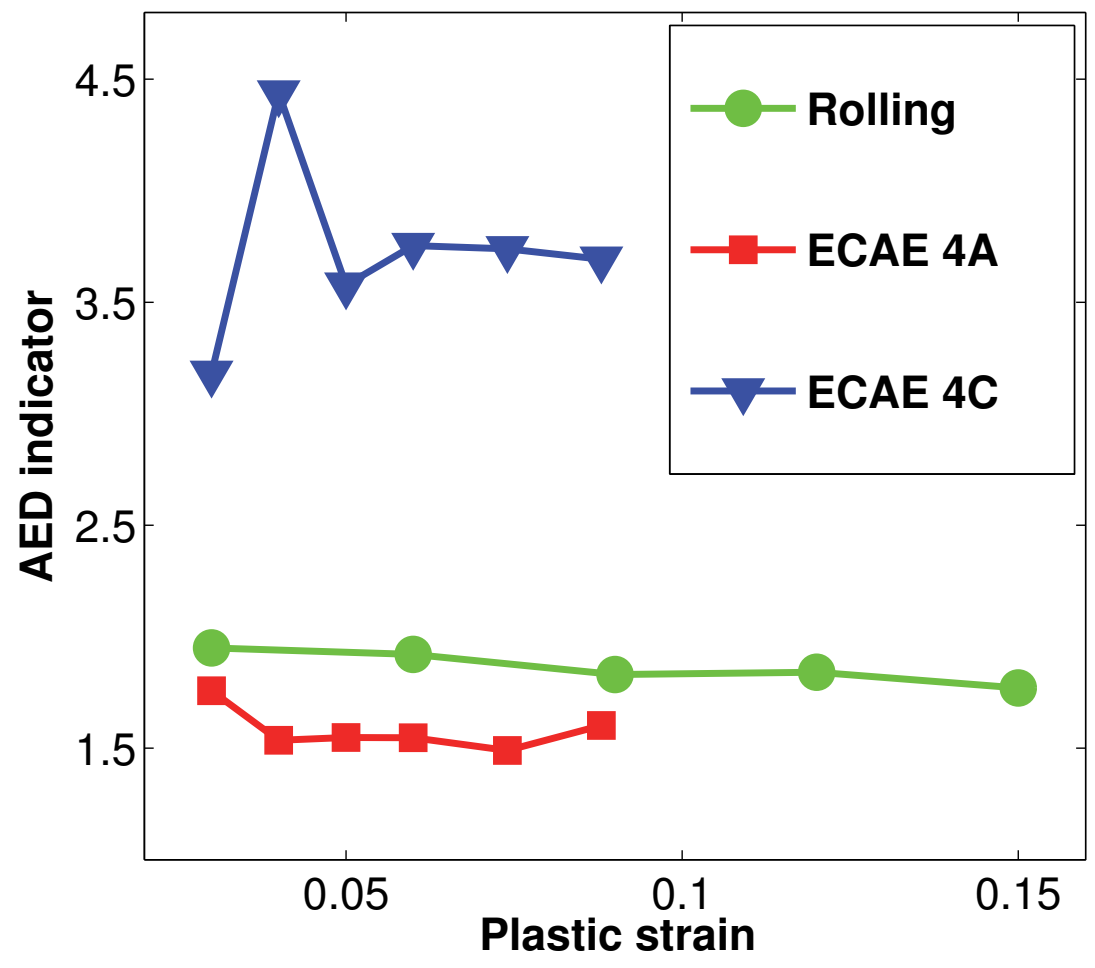

Figure 13: Evolution of AED index in compression with strain for as-received, $4 \mathrm{~A}$ and $4 \mathrm{C}$ materials. 


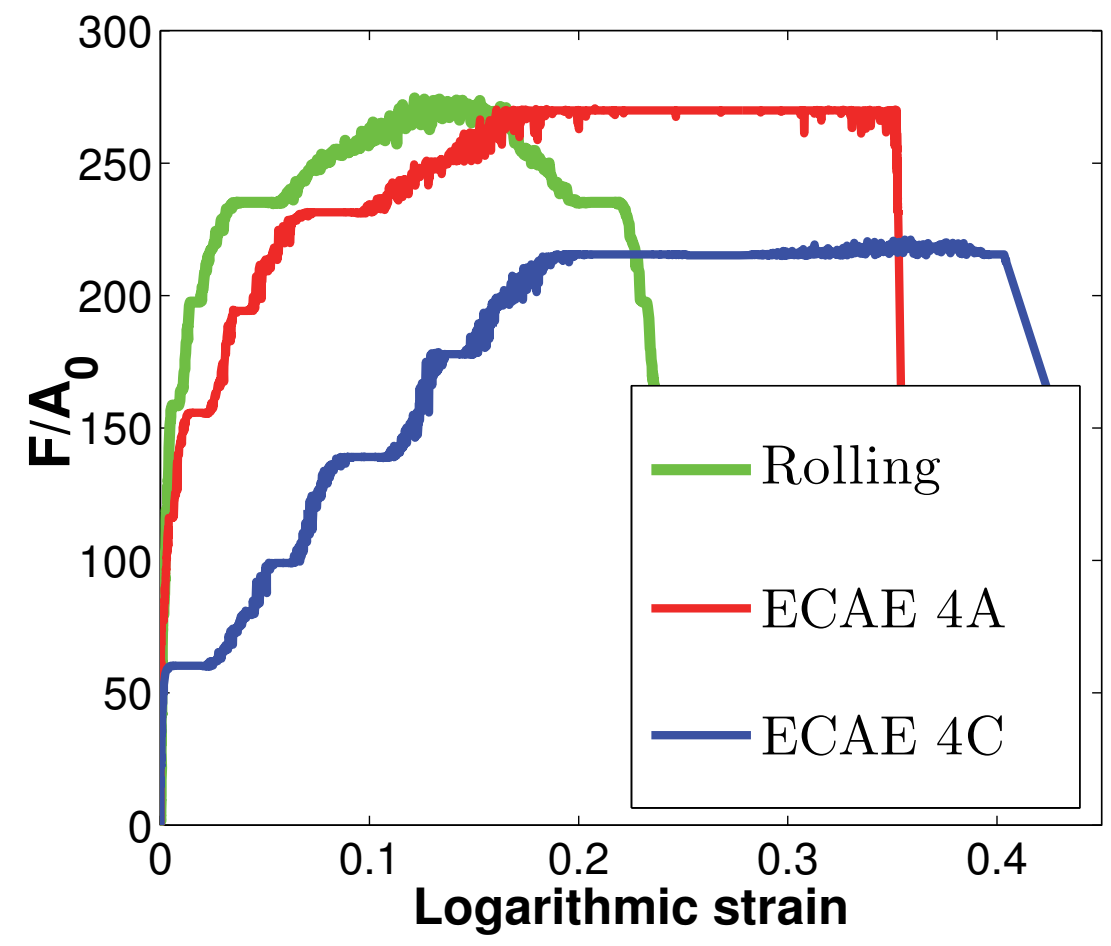

Figure 14: Nominal axial stress versus logarithmic strain for the RN10 notched bars of as-received and ECAE processed materials. 


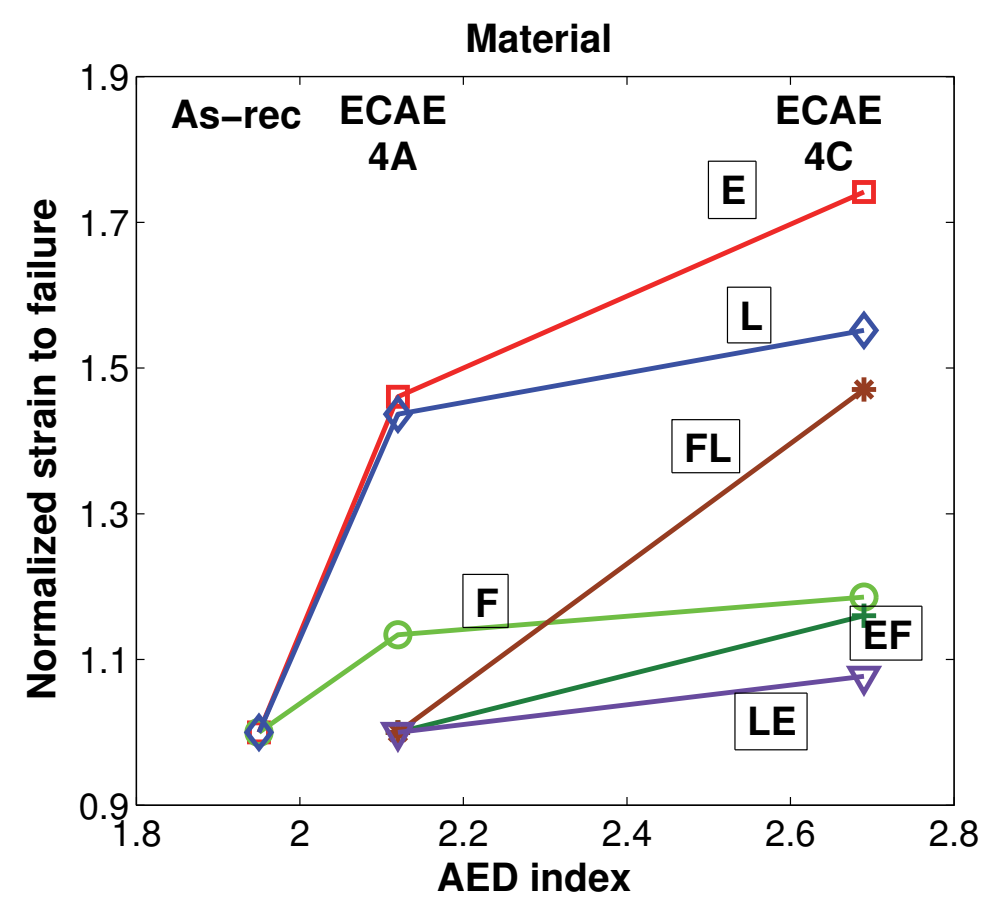

(a)

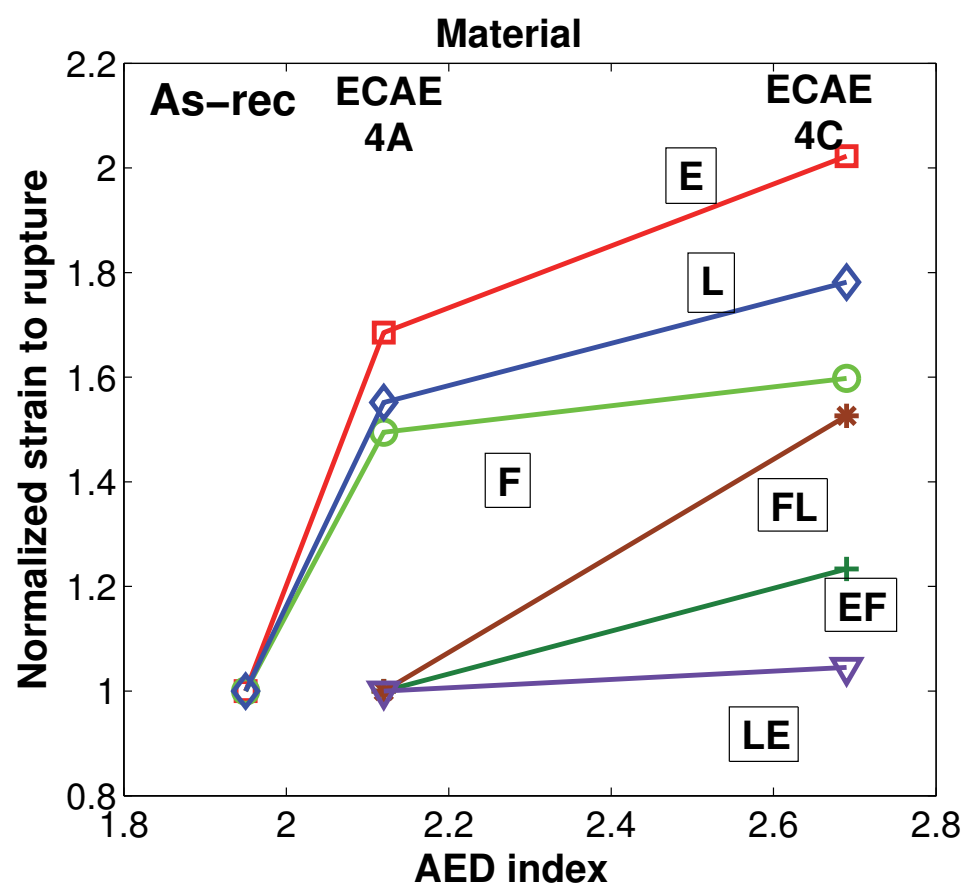

(b)

Figure 15: Correlation between the AED index and the improvement in ductility along six loading orientations using: (a) the strain to failure initiation, and (b) the strain to rupture. The ordinate is normalized by the smallest value of ductility along a particular direction, which is the value for the as-received material when available. In the off-axis directions, the values of $4 \mathrm{~A}$ material were used. 


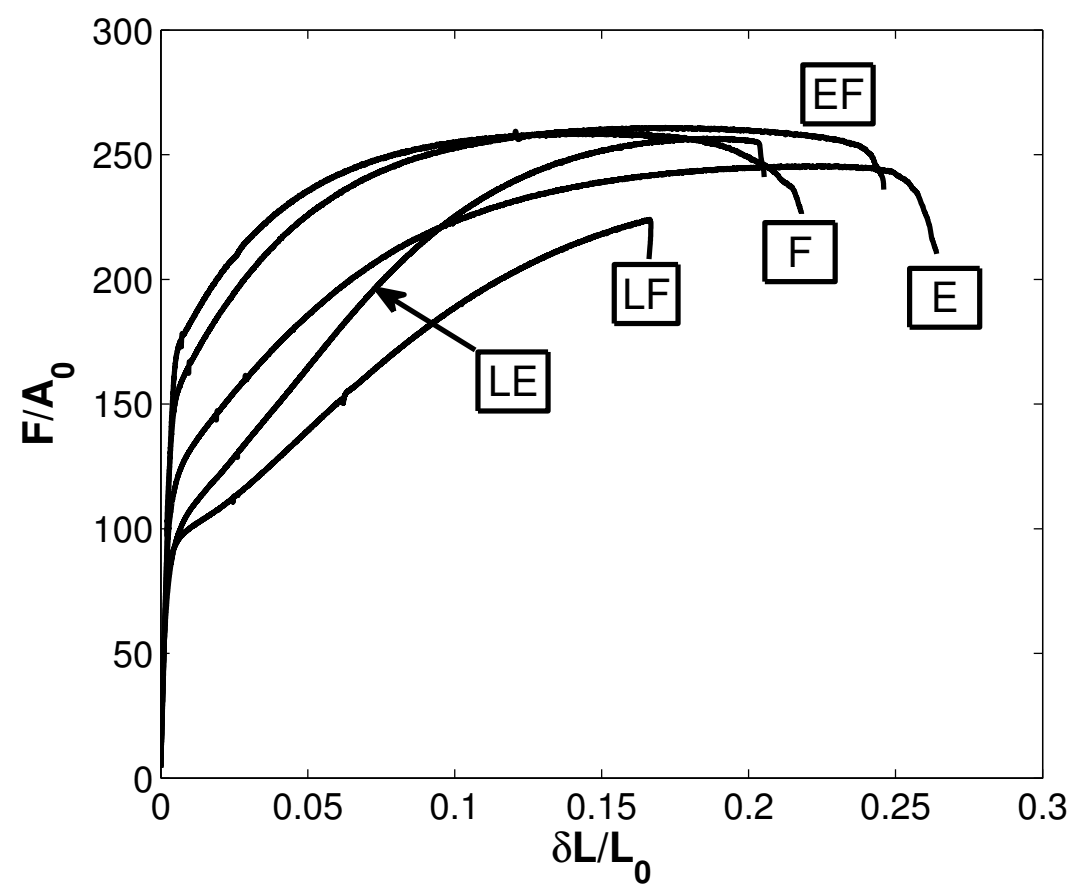

(a)

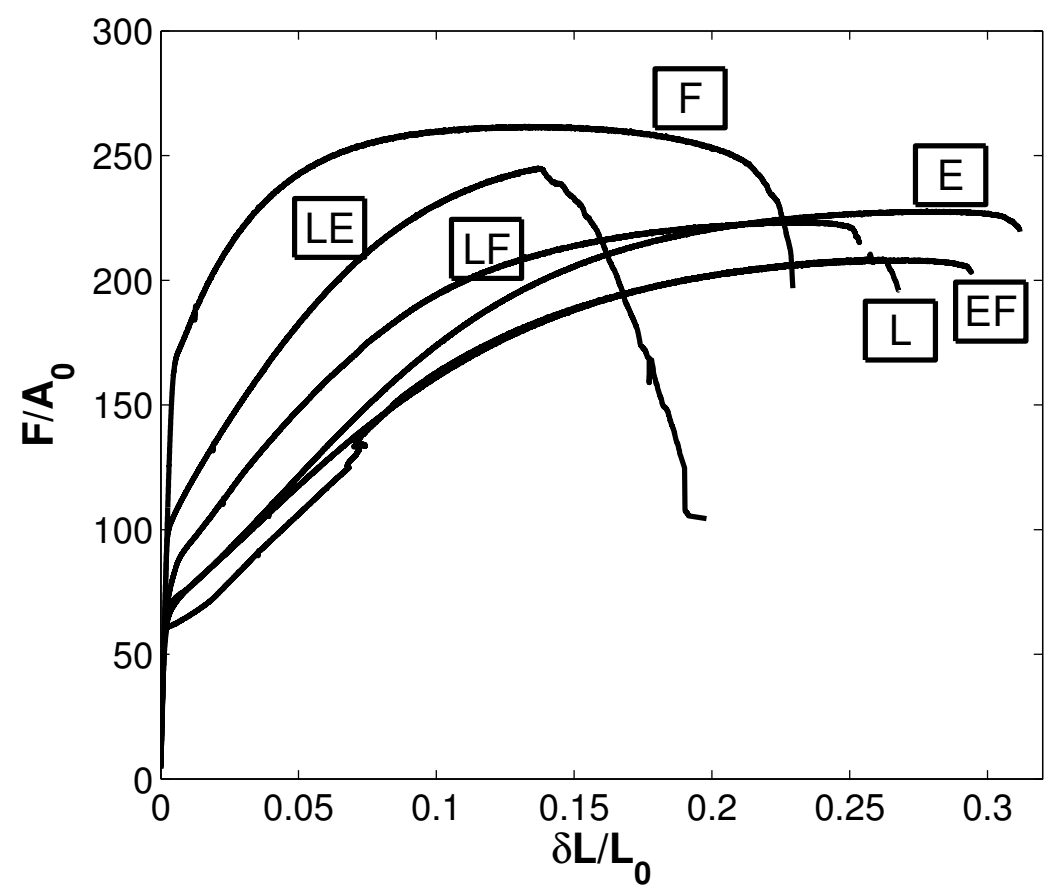

(b)

Figure 16: Nominal stress-strain curves for uniaxial loading in tension along the three principal and three off-axis directions for (a) ECAE 4A and (b) ECAE 4C materials. 

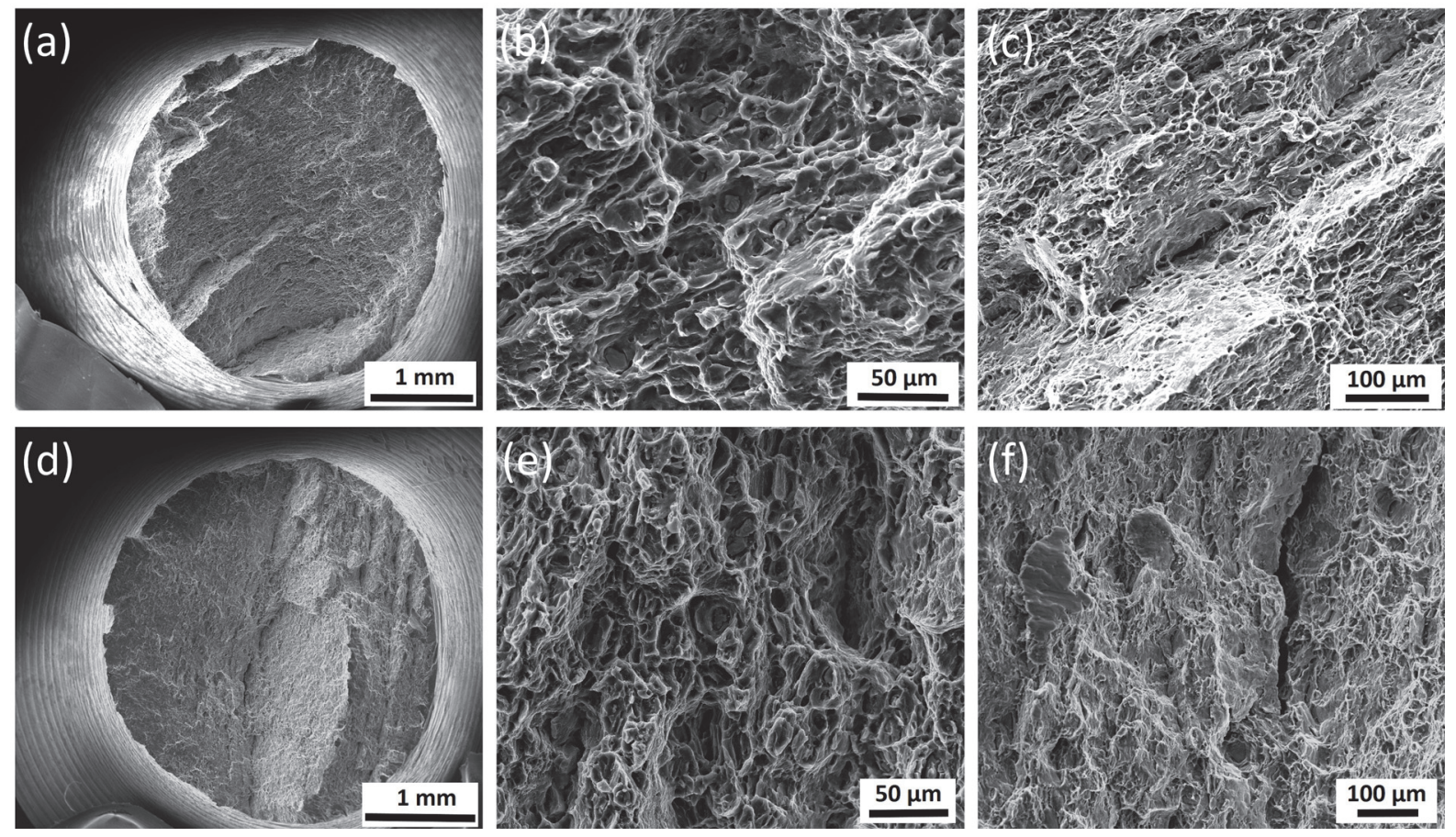

Figure 17: Fracture surfaces of RN10 specimens (a)-(c) ECAE 4A and (d)-(f) ECAE 4C materials showing dimpled character. 


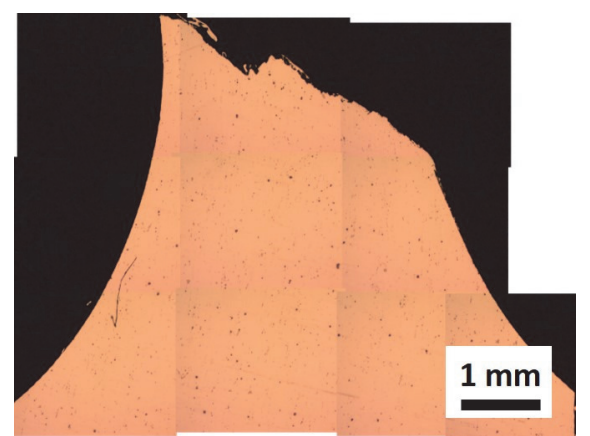

(a)

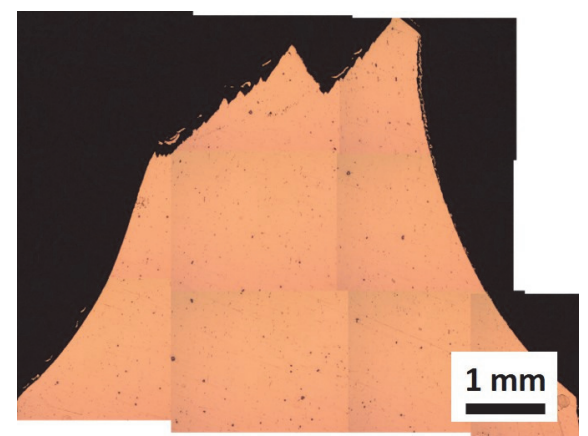

(b)

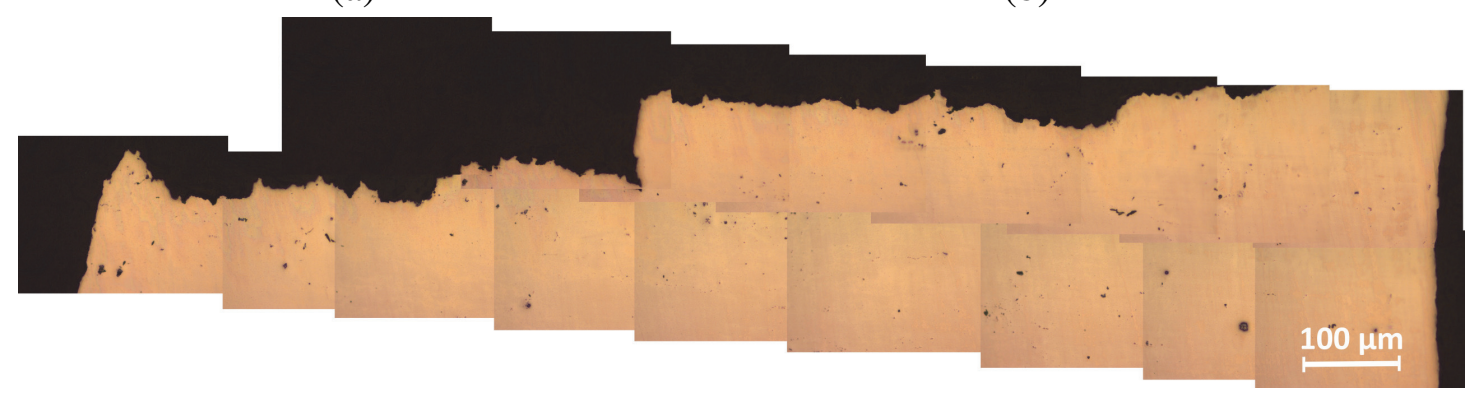

(c)

Figure 18: Profile of fractured RN10 specimens showing macroscopic failure mode (a) 4A RN10 bar, (b) 4C RN10 bar in the E-L plane. (c) Stitched optical microscopy images of an other 4C RN10 bar in the E-F plane perpendicular to the plane shown in (b). 


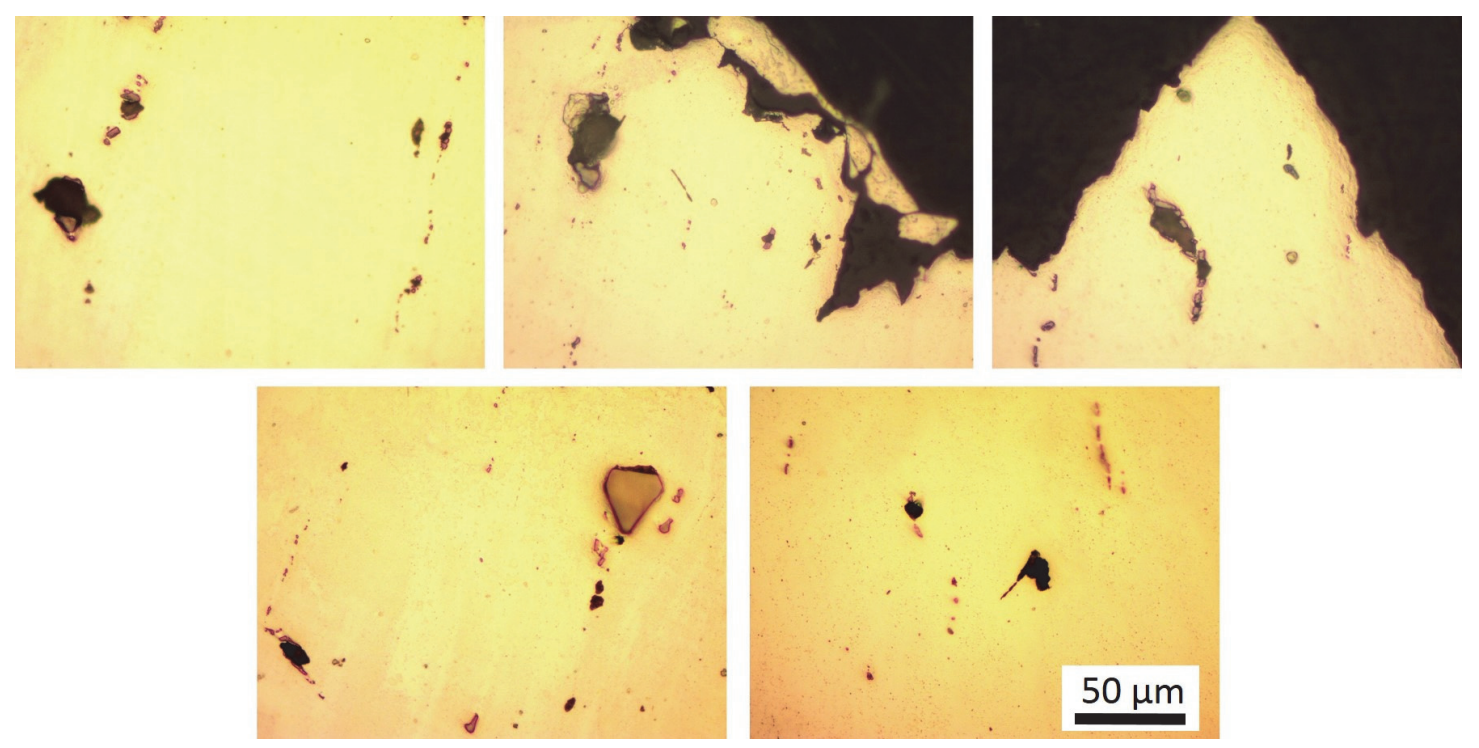

Figure 19: Magnified images capturing some damage initiation sites underneath the fracture surface of the RN10 4C bar shown in the E-F plane as in .. 18c. 

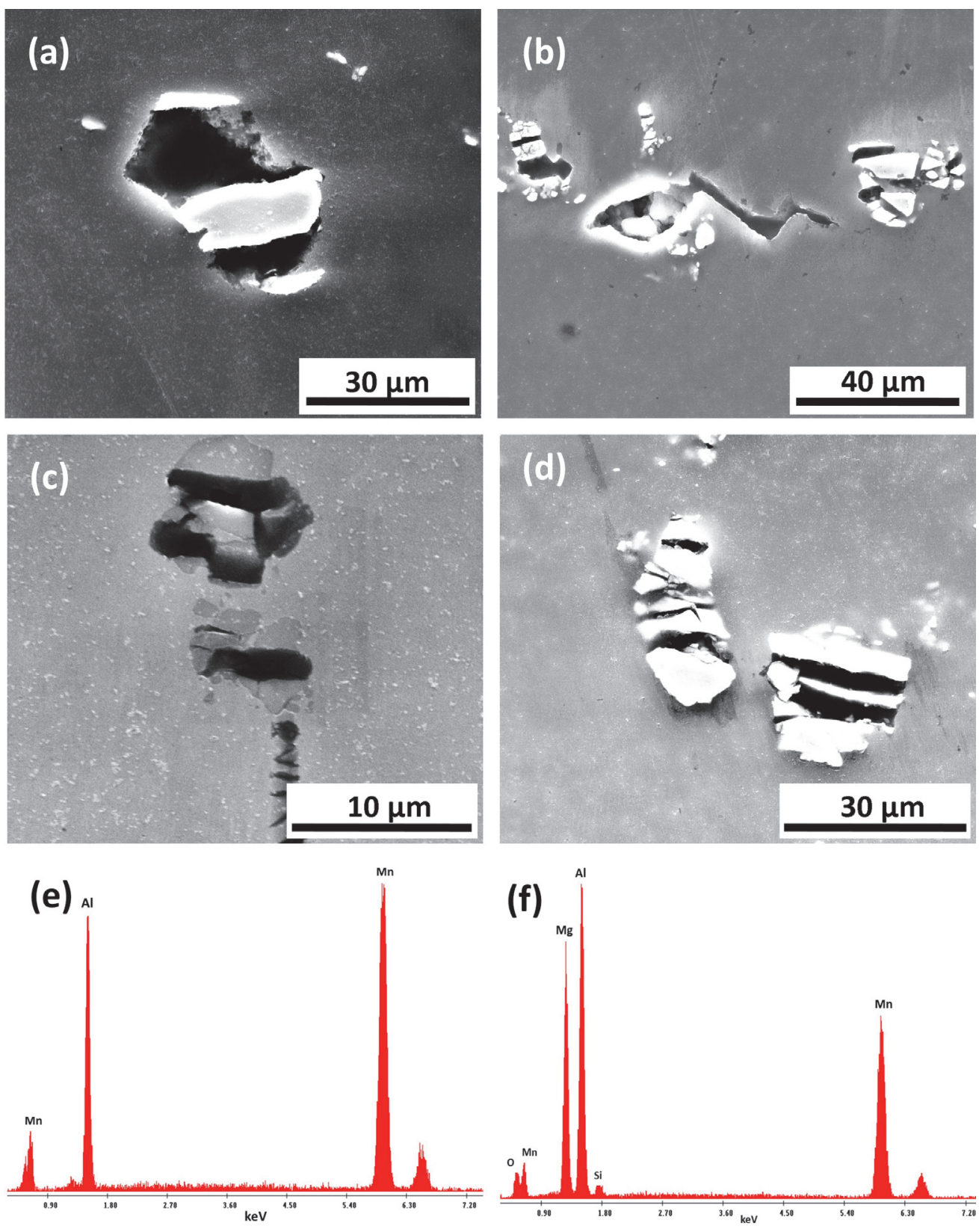

Figure 20: SEM images showing damage initialtion sites in the E-F plane along with EDS spectra of the particles involved in void nucleation. 


\section{Appendix A. From strain ratios to anisotropy coefficients}

The following relationships hold between the anisotropy coefficients entering the quadratic Hill criterion (1) and the strain ratios defined in Section 3.3.2:

$$
\begin{gathered}
\frac{h_{\mathrm{F}}}{h_{\mathrm{E}}}=1-\frac{3\left(R^{\mathrm{E}} R^{\mathrm{F}}-1\right)}{R^{\mathrm{E}} R^{\mathrm{F}}-2 R^{\mathrm{E}}-2} \\
\frac{h_{\mathrm{L}}}{h_{\mathrm{E}}}=1-\frac{3 R^{\mathrm{E}}\left(R^{\mathrm{F}}-1\right)}{R^{\mathrm{E}} R^{\mathrm{F}}-2 R^{\mathrm{E}}-2} \\
\frac{h_{\mathrm{FL}}}{h_{\mathrm{E}}}=-\frac{1}{2} \frac{\left(2 R^{\mathrm{FL}}+1\right)\left(R^{\mathrm{E}}+1\right)}{R^{\mathrm{E}} R^{\mathrm{F}}-2 R^{\mathrm{E}}-2} \\
\frac{h_{\mathrm{LE}}}{h_{\mathrm{E}}}=-\frac{1}{2} \frac{\left(2 R^{\mathrm{LE}}+1\right)\left(R^{\mathrm{F}}+1\right) R^{\mathrm{E}}}{R^{\mathrm{E}} R^{\mathrm{F}}-2 R^{\mathrm{E}}-2} \\
\frac{h_{\mathrm{EF}}}{h_{\mathrm{E}}}=-\frac{1}{2} \frac{\left(2 R^{\mathrm{EF}}+1\right)\left(R^{\mathrm{E}} R^{\mathrm{F}}+1\right)}{R^{\mathrm{E}} R^{\mathrm{F}}-2 R^{\mathrm{E}}-2}
\end{gathered}
$$

These relations are adapted from [34]; see [42] for details. Since the yield criterion is expressed in terms of the stress deviator only, the yield locus is entirely determined by specifying the above five ratios to any one of the six anisotropy coefficients (here $h_{\mathrm{E}}$ was chosen). If the yield stress $\bar{\sigma}$ appearing on the right hand side of equation (1) is specified, say for uniaxial loading along the E direction, then the following constraint holds:

$$
4 h_{\mathrm{E}}+h_{\mathrm{F}}+h_{\mathrm{L}}=6
$$

which in turn determines the absolute magnitudes of the $h_{i}$ coefficients, hence the AED index in equation (4). 